\title{
MĀORI LANGUAGE USE IN \\ NEW ZEALAND SECONDARY \\ SCHOOLS: WHAT ARE THE ISSUES FOR \\ TEACHERS AND STUDENTS?
}

\section{By Janie Tito}

A thesis submitted in partial fulfilment of the requirements for the degree of

Master of Arts in Māori Studies

Victoria University of Wellington Te Kawa A Māui 


\begin{abstract}
The aim of this study was to examine the issues surrounding Māori language use in secondary schools. This was to test the hypothesis that the learning experience for Māori students is influenced by a school's responsiveness to Māori needs. In particular the focus was on the use of te reo Māori e.g. pronunciation. It was found that when features of te ao Māori are reflected positively in secondary school practices, values and environment, the overall learning experience may be enhanced and become more positive for Māori students. Ultimately such practice has the potential to reduce the disparity between Māori and non-Māori educational achievement. The prevalence and quality of Māori language learning opportunities during and after teacher training, is currently not meeting the needs of students and teachers. This shortcoming requires further research and investigation.

This mixed method qualitative study followed kaupapa Māori research principles and ethics. It incorporated interviews, repeated focus groups and surveys. Participants were teachers and Māori students from selected Wellington secondary schools. The sixty-four student participants raised issues around teachers and their teaching practice. They saw teachers as important role models for positive attitudes and behaviours towards te reo and tikanga Māori. In particular, correct language use and pronunciation was important. The small sample of teachers reported a variety of concerns. One frequent complaint was their lack of knowledge in using te reo and few chances to learn and improve. This study identified a need for more professional development programmes and educational policy to be introduced in secondary schools, which include aspects of Māori language and tikanga learning. This would help address some of the difficulties faced by teachers when using te reo in the classroom and improve overall teaching and learning for Māori students.
\end{abstract}




\section{Intellectual property rights}

This thesis may be used for the purpose of research or private study provided the due acknowledgement is made where appropriate and that the author's written permission is obtained before any material from the thesis is published.

I agree that the Victoria University of Wellington may copy this thesis, in electronic or photocopied form, to supply the collections of other libraries. I also agree that the thesis may be photocopied for supply to any person in accordance with the provision of Section 56 in the Copyright Act 1994. 


\section{Acknowledgements}

First and foremost a huge thanks to the teachers and friends who helped to organise the research within the schools and the schools' management for allowing me to carry out my study. I am extremely grateful to those students who participated in the focus groups and surveys. Your views and experience of school and wider life are so valuable and I feel privileged that you took the time to share it with me. Thank you.

Thanks to the teachers who volunteered to do interviews. You all have such important and interesting experiences in teaching and I value the contributions each of you made to my study.

I am very grateful to my uncle, Dr. George Thomson. Without his advice and guidance I would have been unable to complete this thesis.

Kia ora! to all my friends who have helped me with advice, encouragement and keeping life fun. Also to my partner Troy, who kept me sane and happy during some stressful times.

To the staff of Te Kawa a Māui and my supervisor Peter Adds. Thank you for being helpful and encouraging, and for offering your resources, time and support. I also acknowledge and thank the Victoria University of Wellington for providing resources and financial support.

To my parents, who I thank for allowing me to be myself and follow my own path even if, at times, they didn't understand it or believe in it themselves.

Finally, this is dedicated to my uncle William (Bill) Tito who passed away on the 19th of May, 2007. 


\section{TABLE OF CONTENTS}

Abstract $\quad$ ii

Intellectual property rights $\quad$ iii

Acknowledgements iv

Table of contents vi

List of tables viii

List of figures $\quad$ ix

List of appendixes $\quad \mathrm{X}$

Attestation of authorship xi

Glossary of terms $\quad$ xii 


\section{Table of contents}

Chapter one: Introduction ...................................................... 1

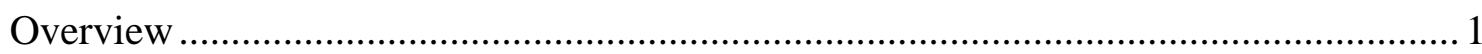

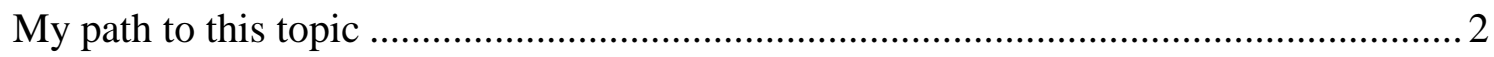

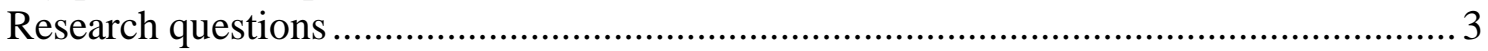

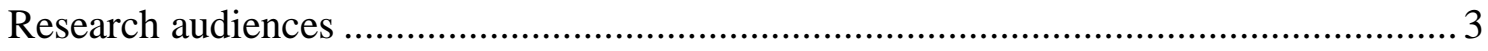

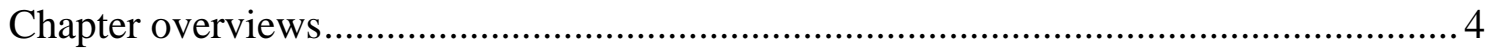

Chapter two: Methodology and methods...............................6

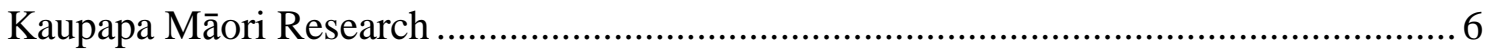

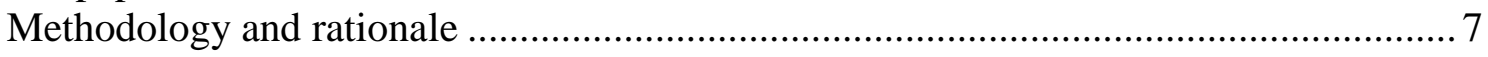

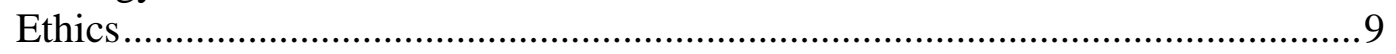

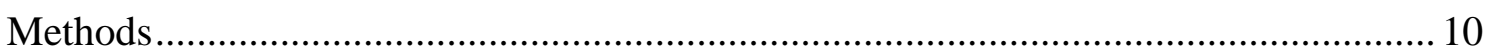

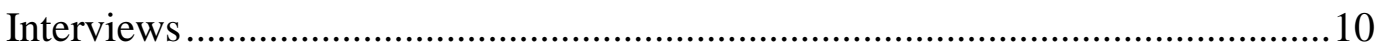

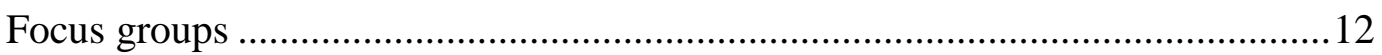

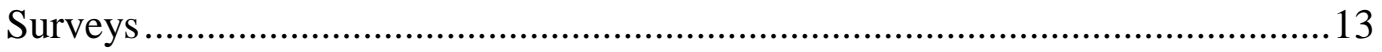

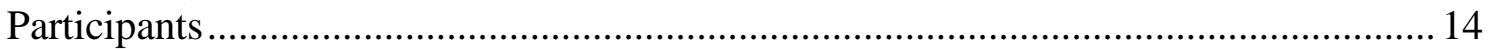

Chapter three: The problem ................................................ 17

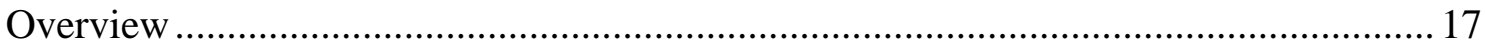

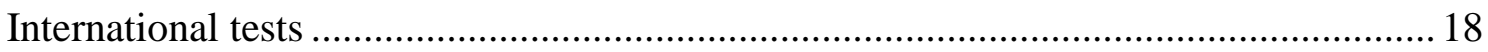

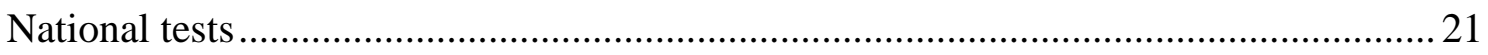

Positive results for Māori - bilingual and immersion schools....................................... 25

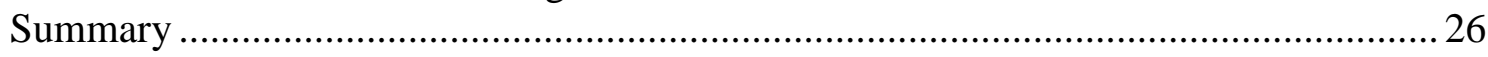

Chapter four: Review of the literature ................................22

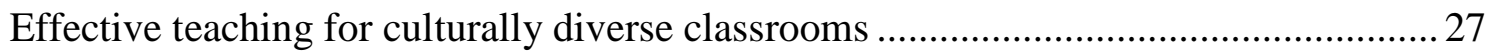

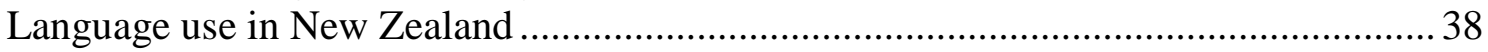

A brief history of te reo Māori ........................................................................ 43

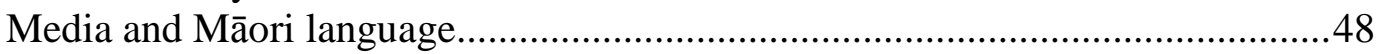

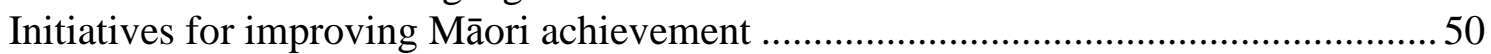

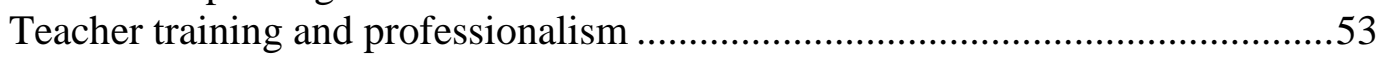

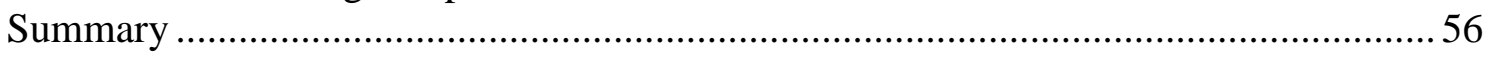

Chapter five: Presentation of findings .......................................58

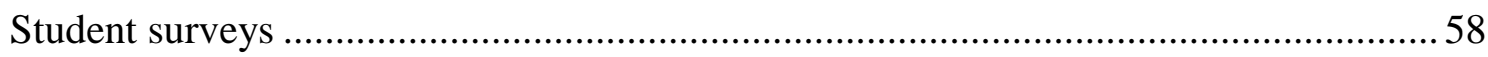

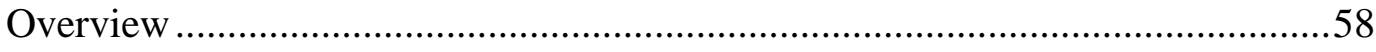

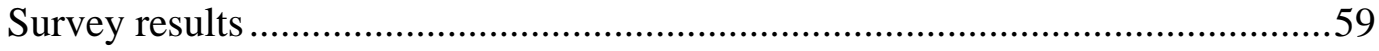

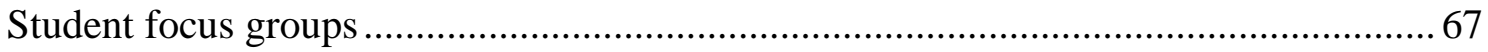

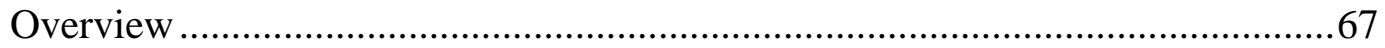

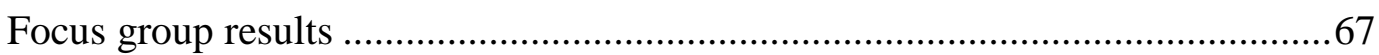

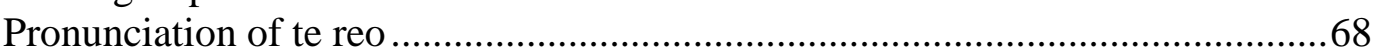

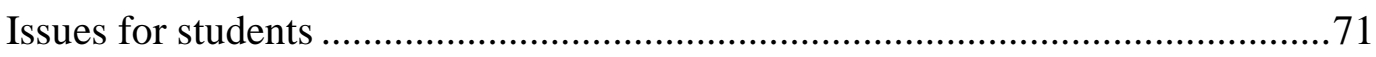

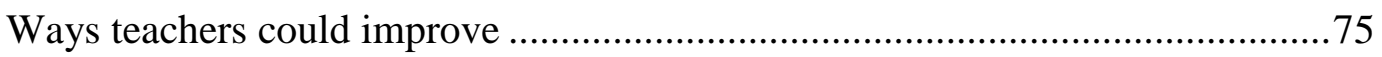

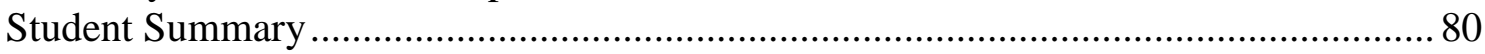

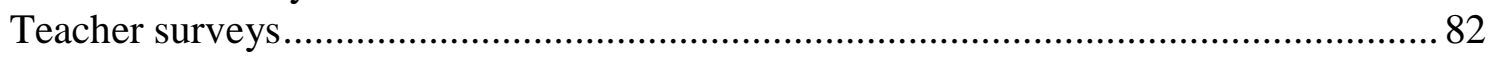

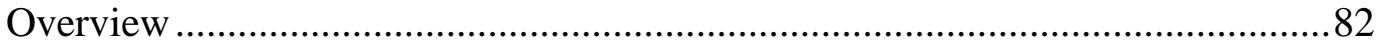

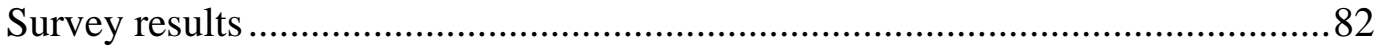

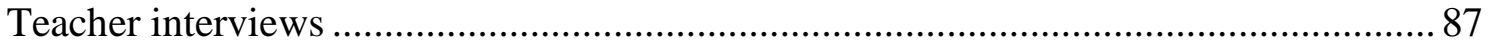

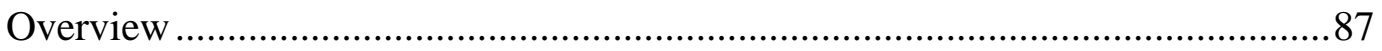




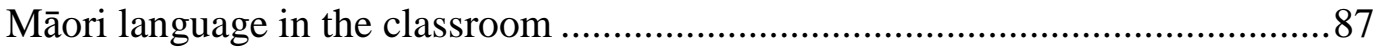

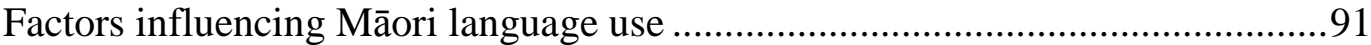

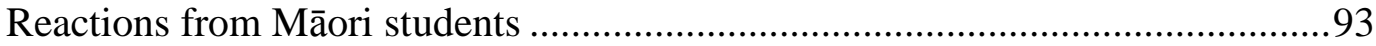

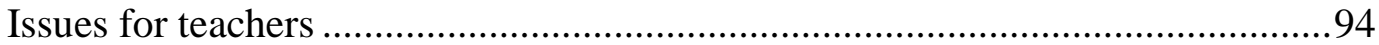

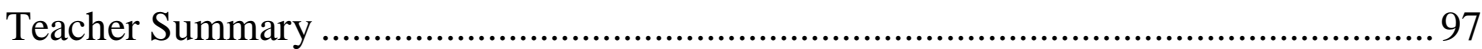

Chapter six: Discussion of findings .................................... 99

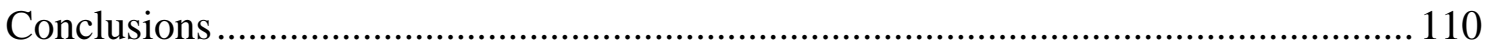

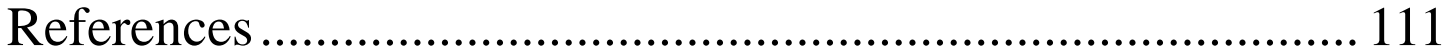

Appendices:

Appendix A. Teacher interview protocol

Appendix B. Teacher survey

Appendix C. Student survey

Appendix D. Teacher information sheet

Appendix E. Student information sheet

Appendix F. Teacher consent form

Appendix G. Student consent form 


\section{List of tables}

Table 1.1 Students leaving without NCEA level 1 in 2005 as a

percentage within each ethnic group..........................................................pg. 22

Table 1.2 Retention rates by ethnicity and age at July 1 st 2005 .....................pg. 23

Table 1.3 Percentage of students leaving school eligible to attend

university 2000-2004 .............................................................................pg. 23

Table 2.1 Percentage of population for types of language speakers in New Zealand pg. 39

Table 2.2 Percentage (rounded) of ethnic groups within New Zealand 'usually resident' population totals for 2001 and 2006 census ........................pg. 40

Table 3.1 Professional standards for secondary teachers ...............................pg. 53 


\section{List of figures}

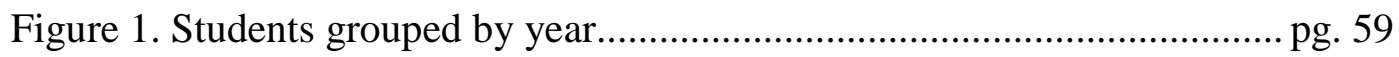

Figure 2. Students' self-assessed Māori language ability ...............................pg. 60

Figure 3. All New Zealanders should pronounce te reo correctly ...................pg. 61

Figure 4. All teachers should pronounce te reo correctly ..............................pg. 62

Figure 5. Number of teachers judged to be mispronouncing te reo .................pg. 63

Figure 6. It is important for teachers to use Māori language in the

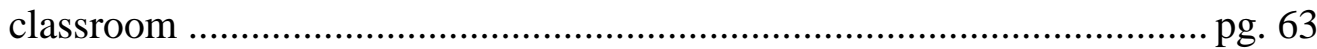




\section{List of appendixes}

Appendix A. Teacher interview protocol...................................................pg. 116

Appendix B. Teacher survey ..................................................................... 117

Appendix C. Student survey ...................................................................pg. 120

Appendix D. Teacher information sheet .................................................... pg. 122

Appendix E. Student information sheet ..................................................... pg. 123

Appendix F. Teacher consent form ............................................................pg. 124

Appendix G. Student consent form ..........................................................pg. 125 


\section{Attestation of authorship}

I hereby declare that this is my own work and that, to the best of my knowledge, it contains no material previously published or written by another person (except where explicitly defined in the acknowledgements), nor material which has been submitted for the award of any other degree or diploma of a university or other institute of higher learning.

Signed: Janie Tito

Date: $13^{\text {th }}$ of March, 2008 


\section{Glossary of terms}

Ātaarangi, Te

Aotearoa

Hapū

Hiringa i te Mahara, Te

Hui

Iwi

Kapa haka

Kauhua, Te

Kaumātua

Kaupapa Māori

Kei te pēhea koe?

Kia ora!

Kōhanga reo

Kotahitanga, Te

Kura kaupapa

Marae

Mātauranga

Matua
An immersion style of te reo language learning and teaching

(location) Māori name for New Zealand

(noun) clan, tribe, subtribe - section of a large tribe

(name) 'The power of the mind'

(noun) gathering, meeting, assembly, seminar, conference

(noun) tribe, nation, people, race

(noun) concert party, haka group, Māori cultural group, Māori performing group

(name) meaning supports on a waka that support the steering of the waka forward. It is a metaphor expressing the need for all those working to improve Māori student outcomes to have a shared understanding of what is required to work together for that purpose

(noun) adult, elder, elderly man, elderly woman

Māori ideology

(greeting) How are you?

(interjection) hello! cheers! good luck! best wishes!

Māori language preschool

(noun) unity

(noun) school operating under Māori custom and using Māori as the medium of instruction

(noun) courtyard - the open area in front of the wharenui, where formal greetings and discussions take place. Often also used to include the complex of buildings around the marae

(noun) education, knowledge, wisdom, understanding, skill

(noun) father, parent, uncle 
Moa

Mōrena

Pākehā

Pōwhiri

Pūtahitanga Mātauranga, $\mathrm{Te}$

Taitokerau, Te

Tangata whenua

Tangi (or tangihanga)

Te Ao Māori

Tikanga

Tukutuku

Waiata

Wairua

Whaikōrero

Whakapapa

Whakawhanaungatanga

Whānau

Whanaungatanga

Wharenui (noun) large extinct flightless birds of several subspecies

(greeting) good morning

(noun) New Zealander of European descent

(noun) invitation, rituals of encounter, welcome ceremony on a marae

(name) 'Excellence in education through unity'

(location) The far north area of the North Island

(noun) local people, hosts, indigenous people of the land - people born of the whenua, i.e. of the placenta and of the land where the people's ancestors have lived and where their placentas are buried

(noun) weeping, crying, sound, funeral, rites for the dead

The Māori world

(noun) correct procedure, custom, habit, lore, method, manner, rule, way, code, meaning, reason, plan, practice, convention

(noun) ornamental lattice-work, used particularly between carvings around the walls of meeting houses

(noun) song, chant, psalm

(noun) spirit, soul, quintessence - spirit of a person which exists beyond death

(noun) oratory, oration

(noun) genealogy, genealogical table, lineage, descent

(verb) to create whanaungatanga

(noun) extended family, family group, a familiar term of address to a number of people

(noun) relationship, kinship, sense of family connection

(noun) meeting house, large house - main building of a marae where guests are accommodated. Traditionally the wharenui belonged to a hapū or whânau but modern 
meeting houses have been built for non-tribal groups, including schools and tertiary institutions. Many are decorated with carvings, rafter paintings and tukutuku panels

The definitions given are those most closely describing the words as used in the current context. Many of these kupu or words may have several alternative meanings. These definitions are from the online Māori dictionary at $\underline{\text { www.maoridictionary.co.nz }}$ 


\section{Chapter one: Introduction}

\section{Overview}

There have been a number of positive developments in the area of Māori education over the past decade. However, statistics clearly show ongoing discrepancies between Māori and Pākehā particularly in terms of educational achievement. Underlying these discrepancies is a number of factors which may include more negative school experiences for Māori. In 'Te Kotahitanga Project' (Berryman \& Bishop 2006: 20) Māori secondary school students stated that mispronunciation of Māori language was a factor in making schooling a negative experience. The purpose of this qualitative study is to understand the issues surrounding Māori language use in the classroom, for both teachers and Māori students, in selected Wellington secondary schools. For example, pronunciation may not be the only issue for students. They may appreciate teachers consistently attempting to pronounce te reo correctly, but would like it used more often. Teachers, on the other hand, may encounter barriers such as lack of knowledge or confidence in using te reo.

Identifying what the issues are for both groups will have implications for the type of professional development, training and support offered to teachers. If Berryman and Bishop (2006) are correct in their conclusions the relationship between students and teachers could also improve with better communication and understanding in terms of the use of Māori language in the classroom. 


\section{My path to this topic}

I have been a secondary teacher for four years in London and New Zealand. The last few years have been at a mid-size, country school in the Waikato which was generally a very enjoyable experience. New Zealand students can be a pleasure to work with especially compared to the difficult behaviour exhibited by students in many London schools. When I visited New Zealand during the foreshore and seabed debates of 2003 I noticed a strong anti-Māori view encouraged by media and a lack of understanding by the public of the issues for Māori. This was a disappointment to me and it made me wonder about the level of education we receive regarding Māori history and culture in general. I thought back to my own schooling and the lack of teaching of te ao Māori. Then later at the College of Education, where a lot of my colleagues had little or no experience with Māori or Pacifika people or language. The Māori language and tikanga course at the College seemed to be so basic it appeared more as a token gesture.

The biggest factor influencing the choice of this topic was my experience in teaching. Many teachers in my school still mispronounced Māori language and Māori students' names. On many occasions I witnessed the deep discomfort and shame this caused students who were already struggling in the school system and who were only just managing to stay engaged. I had assumed, wrongly, that younger or newly qualified teachers would have more experience with Māori language through their training and better attitudes towards its use. However, these relatively young and therefore 'cool' teachers continue to mispronounce personal and place names. They are perpetuating the potential for a negative schooling experience for Māori students in their classes and setting bad examples for non-Māori and Māori alike. I could not believe it when in one instance a student told me she had changed 
her beautiful Māori name, to one more English-sounding, because she was tired of being embarrassed when teachers said it wrong.

These and many other experiences made me think about the quality of teacher training and what I could do to help improve the use of te reo by teachers. In turn, I thought that perhaps this might help make the schooling environment more positive for Māori, with the ultimate aim of improving their academic achievement.

\section{Research questions}

In order to address these issues the research questions that have been selected are:

1. How does the way Māori language is, or is not, used in the classroom (including factors such as tone, style or pronunciation) impact the learning of Māori students?

2. Can the holistic schooling experience become more positive for Māori by enhancing the use of te reo by teachers and students?

3. In this context what does 'enhance' mean for Māori students?

4. What are the issues for teachers when they do, or do not, use Māori language in the classroom including any needs for further professional development and support?

\section{Research audiences}

This research was carried out for the benefit of Māori students in New Zealand and they are an important audience of the results of this work. Other audiences include teachers and management in secondary and other schools. Policy makers in education and language roles will also be interested in the findings of this study, as it could have potential for use in a range of sectors. 


\section{Chapter overviews}

Chapter one introduces the topic and how it came to be the focus of this research. It identifies the research questions and target audiences.

Chapter two presents the methodology and methods used. It discusses the theoretical basis of Kaupapa Māori which underpins the current research. It explains the rationale behind the methods used, such as interviewing and Māori focussed ethics. Participants of this study are descriibed. Methods are presented which include focus groups, student surveys, teacher interviews and teacher surveys.

Chapter three looks at education results for Māori secondary school students since the 1980s. It presents results from international and national studies and uses these to compare achievement across different learning areas and student age groups. The chapter offers evidence to suggest that Māori face massive challenges in education and are clearly not achieving at a standard comparable with other ethnicities in New Zealand.

Chapter four reviews literature relevant to Māori education and language. It presents ideas on several different theories which attempt to explain the gap in educational achievement found between Māori and other ethnicities. The literature on this topic is found to be wide ranging, at times confusing and offers no clear consensus on the reason for educational disparity. However, the literature used by New Zealand's Ministry of Education is presented as an important insight to the direction taken by education policy-makers. The chapter also discusses the use of language in New Zealand including types of languages spoken and general attitudes of New Zealanders to foreign languages and te reo Māori. A summarised history of the Māori language is presented and a current snapshot of its use today including a brief discussion on the role that media has in influencing language use. Some current 
initiatives for improving Māori educational achievement are discussed as well as teacher training and professional standards.

Chapter five offers a presentation of the results. It is organised into results for students by surveys and focus groups and then the results for teachers by surveys and interviews. A summary is given of each group's results.

Chapter six discusses the findings. It analyses the results and looks at how effectively the research questions have been answered, if appropriate. The strengths and weaknesses of the current study are identified and suggestions for further research are made. Finally the conclusions of this study are presented. 


\section{Chapter two: Methodology and methods}

\section{Kaupapa Māori Research}

Māori initiated research has been carried out in Aotearoa over the last decade, usually within a wider movement of kaupapa Māori research (Bishop 1996; Pihama 1993; Graham Hingangaroa Smith 1997; Smith Tuhiwai 1999). This is generally described as a philosophical and practical framework that has been applied successfully in education and research in Aotearoa. It has also been used in alternative school systems such as kura kaupapa and kohanga reo, and in small and large scale research projects within education (Bishop et al. 2003).

Most relevant literature shows that it is difficult to define kaupapa Māori and even more so to develop a common research methodology. However, as Bishop (1996: 15) notes, kaupapa Māori theory does not offer potential researchers a method which has predictability or replicability, but a culturally responsive and appropriate 'way of doing', one that has Māori cultural preferences, practices and aspirations at the forefront. In fact, it may not be appropriate to search for a specific method since what Pākehā researchers may call methodology, Māori call 'kaupapa Māori research' (Smith Tuhiwai 1999: 125). Graham Smith (1990) provides a helpful summary of the many different views regarding kaupapa Māori. He suggests that this kaupapa is:

- related to being Māori and based on Māori philosophy and principles

- sees the Māori world and ways of knowing as being valid and legitimate

- highlights the importance of Māori language and culture

- is about the "struggle for autonomy over our own cultural wellbeing" 


\section{Methodology and rationale}

There are some ways of turning the theory of kaupapa Māori into practical research methods. Bishop and Glynn (1999: 129) have provided an excellent basis for developing a Māori-focussed research by asking questions related to initiation, benefits, representation, legitimation and accountability - five factors that address the main concern of kaupapa Māori in practice, that is, power and control.

\section{$\underline{\text { Initiation }}$}

Who initiates the project?

What are the goals of the project?

Who sets the goals?

Who sets the questions?

Who designs the work?

\section{$\underline{\text { Benefits }}$}

What benefits will there be for the researched group?

Who will get the benefits?

What systems of assessment and evaluation will be used?

What difference will this make for Māori?

How does it support Māori language and cultural aspirations?

\section{$\underline{\text { Representation }}$}

Whose interests, needs and concerns does the text represent?

How were the goals and major questions of the study established?

How were the tasks allocated?

What agency do individuals or groups have?

Whose voice is heard?

Who will do the work? 
$\underline{\text { Legitimation }}$

Who is going to process the data?

Who is going to consider the results of the processing?

What happens to the results?

Who defines what is accurate, true and complete in a text?

Who theorises the findings?

\section{$\underline{\text { Accountability }}$}

Who is the researcher accountable to?

Who is to have accessibility to research findings?

Who has control over the distribution of knowledge?

Bishop and Glynn (1999: 129)

In a meta-study of five research projects within Te Rōpu Rangahau Tikanga Rua (Bicultural Education Research Group) Bishop (1996) examined the studies and research methods in terms of how well they addressed the five main issues as stated above. Bishop used a series of formal, semi-structured, in-depth interviews and informal 'interviews as chats' with the researchers and found this to be a culturally appropriate way of recording the research project 'stories'. Bishop suggests that stories can address researcher hegemony and allow 'diversities of truth to be heard'. Most importantly in terms of kaupapa Māori research, power and control is in the hands of the research participant, as stories are related within their cultural context. They maintain control of the meanings and 'truths' of the story. Through a process of collaboration the stories of the researcher and the participant merge to create new stories Bishop (1996). Native Americans Sunwolf and Frey (2001) also argue that storytelling is a valid and useful tool for researching and recording of personal information. 
The telling of stories may function as providing a way of connecting people, a way of knowing about the world, a way of creating reality, a way of remembering, and a way of visioning the future (Sunwolf \& Frey 2001: 121)

While the context and researcher played an important part in each of the five studies and methods in Bishop's work, it was found that whakawhanaungatanga, whānau and whānau processes were the strongest factors in a successful research strategy. Bishop (1996: 216) identifies three essential and interconnected elements:

- $\quad$ Establishing whānau relationships

- Participant driven approaches to power and control

- Researcher involvement as lived experience

\section{Ethics}

Linda Tuhiwai Smith (1999) offered a code of conduct for Māori researchers, one that is based not on literature, but on her experience within Māori tikanga and common sayings used by kaumātua when advising others:

1. Aroha ki te tangata (have a respect for people)

2. Kanohi kitea (present yourself to people face-to-face)

3. Titiro, whakarongo...korero (look, listen...speak)

4. Manaaki ki te tangata (share and host people, be generous)

5. Kia tupato (be cautious)

6. Kaua e takahia te mana o te tangata (do not trample on the mana of people)

7. Kaua e mahaki (do not flaunt your knowledge)

(Smith Tuhiwai 1999: 120) 


\section{Methods}

The methods used were interviews with the teachers, repeated focus groups with the students and surveys for both groups.

\section{Interviews}

Oakley (1981) looks critically at the traditional forms of interview. She suggests that historically in social research, interviews are seen as a mechanical data gathering exercise, a form of conversation where one person asks questions and the other answers. Traditionally interviewees were passive participants and the role of the interviewer was reduced to asking questions and promoting rapport (Oakley 1981: 36). The relationship between interviewer and interviewee was based upon inequality and unbalanced control of power.

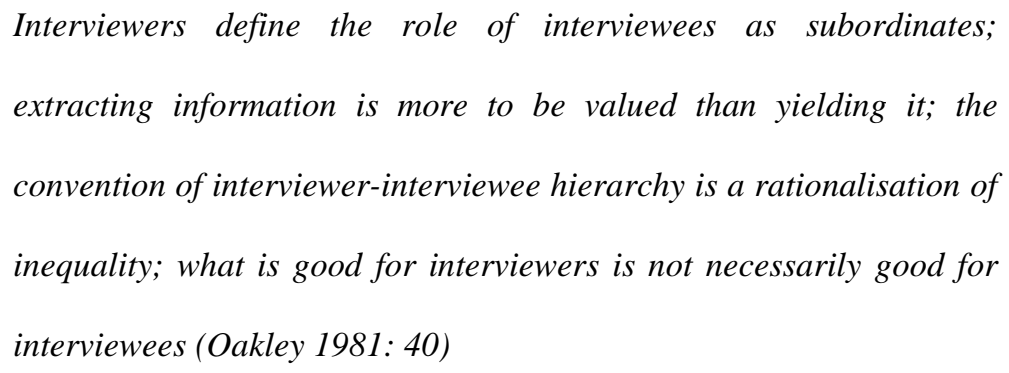

Oakley suggests that to best find out about people, the relationship between the interviewer and interviewee should be non-hierarchical, and that the interviewer needs to share his or her personal identity (41). Laslett and Rapoport discuss 'repeated interviewing'. They suggest that more in-depth information can be gathered by carrying out 'interactive' research. "An attempt is made to generate a collaborative approach to the research which engages both the interviewer and respondent in a joint enterprise" (in Oakley 1981: 44). 
Semi-structured or unstructured interviews (Burgess 1984; Reinharz 1992: 18) or costructured interviews (Tripp 1983) offer a way of encouraging open interaction between the interviewer and interviewee, discussion and clarification of ideas and thoughts (Reinharz 1992: 19). The in-depth interview becomes a 'conversation with a purpose' and offers greater detail and value to research, than just questioning and recording answers (Burgess 1984). In-depth interviews allow participants to contribute using their own words. However, the experiences are understood in terms of what the people mean to say, rather than what they actually said (Tripp 1983).

In the current study, at the initial interviews between researcher and research participants, the research questions were discussed and feedback gained from staff and students as to how appropriate they were. Suggestions were offered of other possible questions. This was to reduce the influence the researcher had on agendasetting and to ensure fair sharing of power in the researcher/participant relationship (Tripp 1983). At this stage it was important to address questions of 'initiation', 'benefits' and 'representation' and to ensure that staff and students were equal participants in deciding the answers. The interview became 'co-structured', and responsibility for providing the answers was shared between both parties. Questions were open-ended rather than closed. This open interaction allowed any assumptions that the interview is based upon to be identified and criticised and helped reveal the existing opinions of the participants, in a world-view context (Tripp 1983: 34). It was important to allow reciprocal design and sharing of control over the structure of the interview, as a way of reducing researcher imposition. "For the interviewer it is as important to learn what questions are important to the interviewee as it is to learn what questions are considered important by the interviewer" (Tripp 1983: 34). 
In order to minimise researcher imposition the next issue to face was how the data is controlled and by whom (Tripp 1983: 34). We needed to address what happens after data has been gathered, and ask who is responsible for writing the final report. Also, who judged it to be a fair representation of the co-authored statements recorded in the interview. This helped address the issues of representation and legitimation advocated by Bishop and Glynn (1999).

Teachers were interviewed in their homes or at their place of work. The interviews took between 15 minutes and one hour. Interview questions are presented in the interview protocol in Appendix A. One interview was held with each teacher and they each filled out a short survey. Interviews were considered appropriate for these participants who are confident in speaking, articulate and willing to share ideas. Using focus groups was determined to be potentially ineffective in this situation. Teachers in a group situation could be motivated to give answers that they want their peers to hear and may not be completely honest. It would also have been difficult to meet with the participants at a time suitable for everyone. These interviews were recorded.

\section{Focus groups}

Focus groups are a good tool for data gathering from a range of participants, in a shorter amount of time than one-on-one interviews. This format is good for situations where the interaction among individuals will help elicit information, especially where the individuals are comfortable with each other and co-operative (Cresswell 2005). Students may be hesitant to provide information in a one-on-one interview format due to a lack of confidence or intimidation in the presence of an unknown adult. Group interviews can also give the participants the power to choose and define the topics or themes discussed (Burgess 1984: 107). Debate and 
discussion between the students can be encouraged and allows for the spontaneity of teenage talk. Their conversations should lead in directions that are meaningful for them, contributing to a 'story' of their experience at school (Burgess 1984: 107). Disadvantages of the focus group format may be difficulty in controlling the discussion while attempting to take notes. It may also be difficult to transcribe the recordings with different voices and dialogue happening.

The focus group in each school was formally begun by the teacher of Māori and included other staff who had volunteered to be interviewed. Students, teachers and the researcher shared introductions. At this point teachers left the room. During the discussion the research was presented to the students. They were then asked to provide feedback on the relevance of the research questions and to offer questions of their own. Students also provided main points for further debate. The discussion lasted approximately one hour after which food was eaten and the meeting closed.

Approximately a week later the second focus group for each school was held. This meeting opened with introductions and a brief summary of the previous discussion topics. The research questions that had been previously agreed on between participants and researcher were then discussed in more detail. Again, this meeting took approximately one hour and it ended with the sharing of food. Both focus group sessions were recorded.

\section{Surveys}

All the teacher participants filled out a short survey containing 13 questions. These provided background information such as age, teaching experience, ethnicity and teacher training. Other forms of data collection such as telephone or email interviews were not appropriate in this research because of the need for face-to-face contact to help establish positive relationships with the participants. Observations 
were not used because this suggests a judgement or marking of criteria of the current level of Māori language used in the classrooms. It is not the purpose of this research to make any judgements on current language use and so observations were unnecessary.

Sixty-four students completed surveys, including those students who participated in discussion groups. This survey is included in Appendix C. These surveys allowed more data to be collected in a short amount of time, and provided some background information on the participants.

\section{Participants}

Participants were teachers and Māori students from secondary schools around the Wellington area. A selection of schools was made from the school information available through the Ministry of Education. This included information on the deciles of the schools. The decile is a socio-economic indicator given to all schools in New Zealand, ranging from 'one' which is a low socio-economic area, to 'ten' being a high or rich socio-economic area. Other important factors in the selection were the status as single-sex and co-educational schools, and overall school size. In most New Zealand schools Māori are a minority group, so schools were chosen to reflect this, by having minority Māori student populations. Four schools were initially identified as appropriate based on the selection criteria. These were chosen from the 32 secondary schools in the Wellington region. Of these four schools the final two were selected, and represented an inner city school and one based in the suburbs, a single sex and co-educational school. A major factor in choosing these two schools was the researcher's previous experience working within the school and/ or contact with a teacher who was able to help facilitate this research in action. 
Without such prior contact it would have been very difficult to gain access to the school and time with the students and teachers. If more than two schools were approached the research process would have taken too long.

Emails were sent to the Principals and also to the teachers of Māori language at each of the schools selected. This gave information about the research and asked for the school to volunteer. A follow-up call was made to the Principal to answer any further questions and to offer a face-to-face meeting with them. The teacher of Māori was an important part of the process. They tend to have more contact and knowledge of the Māori students in the school, and could assist with the formal process of entering the school and meeting with the teachers and students. This was in a way, similar to that of tangata whenua guiding the process of an outside group visiting a marae. It was very difficult to make initial contact with the school management. It was a busy time of year, at the beginning of the school term. Once contact was made, Principals' were reluctant to agree to any sort of time or staffing commitment and the key factor in gaining entrance into a school became the personal knowledge by the researcher of the school and/ or staff members. In all cases the rest of the communication and organisation was between the researcher and the teacher known to them in each school.

The level or amount of Māori language used in the classroom is likely to be influenced by the subject curriculum. For example, social studies or geography teachers would be expected to encounter Māori place names on a regular basis. The teachers who volunteered to take part in the research came from a range of subjects. They were selected from classroom teachers only. The research is focussed on what is happening in the classroom, and subject teachers can offer first-hand experience as compared to the observations of non-teaching staff. The teachers came from a 
variety of cultural backgrounds. Their experience in teaching ranged from a new graduate to 20 years teaching experience.

Once the school Principal confirmed that the research could go ahead, a visit was then arranged. The teachers were met during their own time after school hours, while students were met at lunch times on the school premises. It was important to respect the wishes and needs of the school in organising this contact time, to minimise disruption to classes and schedules.

The first focus group time was arranged with the students through the contact teacher and/ or the teacher of Māori. These teachers asked Māori students from their classes, or throughout the wider school, to volunteer. The only criteria specified for volunteers was that they were selected from different year groups and where possible an even number of genders. In both schools the focus group included between five and seven students. The students who participated in the focus groups completed the survey. The teachers of Māori then asked all of the students in their te reo classes to fill out the survey. There were no students from these classes who chose not to do the survey.

The next chapter looks at education results for Māori secondary school students since the 1980s. It presents results from international and national studies and uses these to compare achievement across different learning areas and student age groups. The chapter offers evidence to suggest that Māori face massive challenges in education and are clearly not achieving at a standard comparable with other ethnicities in New Zealand. 


\section{Chapter three: The problem}

Judged by the system's own standards Māori children are not being successfully taught and for this reason alone, quite apart from a duty to protect the Māori language, the education system is being operated in breach of the treaty (Waitangi Tribunal 1986: 58)

\section{Overview}

In the Education Department's Educational Attainment Report (1983/84) statistics showed seventy-six percent of Māori children left school without at least three school certificate subjects (Year 11/ NCEA Level One equivalent). This compared to thirty-seven percent of Pākehā children. The Waitangi Tribunal, in their 1986 recommendations, noted that "educational policy over many years and the effect of the media in using almost nothing but English has swamped the Māori language and done it great harm" (Waitangi Tribunal 1986: 5). There is increasing evidence that since the 1980s little has changed for Māori educational achievement or the language. New Zealand is one of the only western countries where the gap between the achievers and non-achievers is getting bigger (John Hattie 2003: 3). Māori students continue to be most at risk of under-achieving and in the bottom twenty percent of achievers Māori students are a growing proportion (John Hattie 2003). There are many studies in New Zealand and overseas that provide statistical evidence of student achievement in different domains of learning, for different age groups and ethnicities. These are useful in providing comparisons of achievement levels for Māori against other groups of learners. 


\section{International tests}

There are several international benchmarks by which we can compare Māori students' achievement to various groups here and overseas. Each of these studies clearly shows major deficits between the level of achievement of Māori students and adults compared to other ethnicities.

The 'Trends in International Maths and Science Study' or TIMSS, is organised by the International Association for the Evaluation of Educational Achievement (IEA). The study is carried out by educators in an attempt to compare achievement in maths and science across nations. It is generally accepted to be one of the largest and best-controlled studies of its kind. Approximately 80 countries were involved in 2003 with 500 schools and 19,000 students. The same groups will be tested again in 2007 at eight-10 years of age, 12-14 years or both. In comparing results for 1994 and 2002 it was found that year nine Māori students performed significantly worse in maths than Pākehā and were below the national average (Ministry of Education 2004b). In 1994 Pākehā had a mean score of 517 and Māori 463 with a national average of 501. In 2002 these figures showed no significant changes. Pākehā scored 510 and Māori 458, compared to a national average of 494 (Ministry of Education 2004b: 10). Although it could be argued that Māori are improving gradually in relation to the average figure for the country, the gap between groups continues.

The Programme for International Student Achievement (PISA) is administered by the Organisation for Economic Cooperation and Development (OECD) and surveys 15 year olds (students in year 10 or 11) in over 30 OECD countries. Although the TIMSS data showed that performance in maths was worse for Māori than for Pākehā at year nine, PISA reported that in 2000, Māori achievement in maths was comparable to the OECD mean. This could indicate some improvement 
in maths for Māori who stay engaged in school till at least year 11. However, within New Zealand there were still significantly worse results across all subject domains for Māori than for Pākehā and Asian students. Performance in reading and science was notably lower than the OECD mean. Literacy in particular was poor, as there was a high number of Māori in the lower end of the literacy scale (Ministry of Education 2004a: 3). As the report noted this has the potential to produce school leavers with low literacy skills leading to worse prospects for employment (Ministry of Education 2004a: 5).

UNICEF (United Nations Children's Fund or originally the United Nations International Children's Emergency Fund) uses data from TIMSS and PISA to develop a 'League Table of Educational Disadvantage in Rich Nations' (2002). UNICEF is an organisation dedicated to the welfare of children and also works with the World Health Organisation. Its current aim is establishing long-term human development as well as providing emergency relief and assistance where needed. At the heart of this study is the issue of inequality of learning and it asks: "How far behind are the weakest students being allowed to fall?" According to the organisation's 2002 report some OECD countries are consistently better than others when judged by the proportions of students reaching various achievement standards. Particularly by the size of the gap between low-achieving and average students. In Belgium, New Zealand, Germany and the United States very large gaps are being allowed to open up. Overall New Zealand was 'average' when compared to other OECD countries for educational disadvantage. However, New Zealand ranked twentieth for absolute disadvantage in maths and second to last (in front of Belgium) for 'bottom-end' inequality. This inequality was determined by the level of difference in achievement between children at the bottom and at the middle of each 
countries achievement scale (UNICEF 2002: 9). This is particularly significant when it is noted that a large proportion of students in the bottom-end of achievers in New Zealand are Māori.

The International Adult Literacy Survey (IALS) is a large-scale, international study. It is aimed at comparing, identifying and measuring a range of literacy skills linked to the social and economic characteristics of individuals between (or within) nations. Approximately 26 countries have participated to date. In each country samples of adults aged between 16 and 65 were interviewed and tested in their homes using the same literacy test. The main purpose of the survey was to find out how well adults use information to function in society. Another aim was to investigate the factors that influence literacy proficiency and to compare these between countries. The 1996 survey showed that approximately one in five adults in New Zealand had extremely poor literacy ability. This group was most likely to be made up of Māori, Pacifika or other non-European ethnicities (Ministry of Education 1997: 2). A key finding was that Māori, Pacifika and other ethnic minority groups had literacy skills below the level of competency judged to be necessary for everyday life (Ministry of Education 1997: 3). This lack of literacy does not only impact on the ethnic groups alone, but also on the nation, as the survey demonstrated a strong link between literacy and a countries economic potential. 


\section{National tests}

Although these international studies provide useful information for educationalists they only cover some areas of the New Zealand curriculum. The National Education Monitoring Project (NEMP) has provided more relevant information about the achievements of New Zealand students using assessment methods customised to New Zealand's school system and curricula. The Ministry of Education has contracted the Educational Assessment Research Unit of the University of Otago to carry out the project. It tests about 3000 students in 260 schools in New Zealand, which are randomly selected. Students are tested at year four and then again at year eight over all curricula areas. Comparisons between data gathered in 1995 and 1999 show that in reading and maths, Māori students did not achieve as well as Pākehā and there was no improvement in results for Māori students over those four years (Ministry of Education 1999: 27).

The main qualification for secondary schools in New Zealand presently is the National Certificate in Educational Achievement or NCEA. The 2005 NCEA results showed that at all three achievement levels there were significantly smaller numbers of Māori gaining qualifications as compared to Pākehā. Ministry of Education figures for school leavers reveal that over 50 percent of Māori boys left school in 2005 without the minimum level one qualification. Māori girls were only just behind with nearly 46 percent leaving without NCEA level one (Ministry of Education 2005). Table 1.1 gives comparisons with other ethnic groups. 
Table 1.1 Students leaving without NCEA level one in 2005 as a percentage within each ethnic group

\begin{tabular}{|l|r|r|}
\hline \multicolumn{1}{|c|}{ Ethnicity } & \multicolumn{1}{c|}{ \% Boys } & \multicolumn{1}{c|}{ \% Girls } \\
\hline Māori & 52.6 & 45.4 \\
\hline Pacifika & 40.9 & 32.1 \\
\hline Pākehā & 25.4 & 17.9 \\
\hline Asian & 13.5 & 7.8 \\
\hline Other & 33.7 & 28.3 \\
\hline
\end{tabular}

Other issues face Māori in our schools such as higher levels of truancy and suspension. In 2005 Māori students were more than twice as likely to be stood down compared to Pākehā students. Suspension, a more serious form of stand-down, rates are also higher for Māori. Overall the suspension rates for Māori are more than three times that of Pākehā and double that of Pacific Island students (Ministry of Education 2005). In 2006 the Ministry of Education released a report showing that the truancy rate of Māori students was more than double that of non-Māori students (Ministry of Education 2006). On a more positive note the proportion of Māori who are excluded from school and the number of exclusions of Māori students have reduced by 18 percent since 2000 (Ministry of Education 2005). However, retention rates of Māori students in mainstream secondary schools are the lowest of all ethnic groups (see table 1.2). 
Table 1.2 Retention rates by ethnicity and age at first of July 2005 (Ministry of Education 2006: 45)

\begin{tabular}{|l|r|r|r|}
\hline \multicolumn{1}{|c|}{ Ethnicity } & Age 16 & Age 17 & Age 18 \\
\hline All* & $80 \%$ & $60 \%$ & $13 \%$ \\
\hline Pākehā & $82 \%$ & $60 \%$ & $11 \%$ \\
\hline Māori & $63 \%$ & $39 \%$ & $8 \%$ \\
\hline Pasifika & $84 \%$ & $66 \%$ & $20 \%$ \\
\hline
\end{tabular}

*Does not include foreign fee-payers or NZAID scholarship students

Low percentages of Māori students leaving school are eligible for entrance to university (table 1.3) although the numbers are slowly increasing.

Table 1.3 Percentages of students leaving school eligible to attend university 2000-2004 (Ministry of Education 2006: 45)

\begin{tabular}{|l|r|r|r|r|}
\hline \multirow{2}{*}{ Year } & \multicolumn{4}{|c|}{ Ethnic Group } \\
\cline { 2 - 5 } & Māori & Pasifika & Asian & Pākehā \\
\hline 2000 & $7 \%$ & $10 \%$ & $52 \%$ & $30 \%$ \\
\hline 2001 & $7 \%$ & $10 \%$ & $54 \%$ & $30 \%$ \\
\hline 2002 & $9 \%$ & $9 \%$ & $52 \%$ & $31 \%$ \\
\hline 2003 & $12 \%$ & $9 \%$ & $54 \%$ & $33 \%$ \\
\hline 2004 & & $14 \%$ & $56 \%$ & $37 \%$ \\
\hline
\end{tabular}

The population of Māori in New Zealand has increased by 30 percent in the last 15 years (Ministry of Statistics 2007: 2). At July 200659 percent of students within New Zealand schools were Pākehā. The next largest group were Māori who accounted for 22 percent of students. This is followed by students of Pasifika (nine 
percent) and Asian (eight percent) ethnicities (Ministry of Education 2007b: 3). Between 2002 and 2006 the numbers of Māori, Pasifika and Asian students increased while the numbers of Pākehā decreased (Ministry of Education 2007b: 4). It is predicted that about 40 percent of primary school students and 35 percent of all secondary students will be of Māori or Pasifika descent by the year 2020 (Ministry of Education 2003: 10). Presently, most Māori students (85 percent) attend mainstream schools (Ministry of Education 2003: 10).

Clearly a large proportion of Māori students are still not engaged in mainstream education in New Zealand and the aims and aspirations of Māori youth are not being fulfilled in the current system. What this means for the government is that not only are Treaty of Waitangi requirements not being met but the nation's wealth in terms of knowledge and economic base will be affected as the population continues to grow and change. However, there is a lot of potential for Māori youth in education and not all achievement levels are poor. This is proven by the results found in Māori based education systems such as kura kaupapa and bilingual schools. 


\section{Positive results for Māori - bilingual and immersion schools}

Māori students can and do achieve well academically as proven in the success of bilingual and immersion education in New Zealand. In 2001 approximately 14 percent of Māori students were enrolled with Māori-medium education providers. This is where teaching is carried out using te reo Māori for a minimum of 31 percent of total teaching time. Reports comparing achievement between 2003-2005 show that the majority of students who take part in bilingual or Māori immersion education gain NCEA qualifications (Ministry of Education 2007a: 3).

This is very significant when compared to mainstream figures for the same period where approximately 40 percent of year 11 Māori students achieved NCEA level one. In mainstream year 12, 50 percent achieved level two and 30 percent of year 13 achieved level three. The literacy abilities of year 11 bilingual and immersion students are particularly strong with about 90 percent gaining NCEA level one literacy requirements by the end of year 11 (Ministry of Education 2007a: 3). In mainstream schools approximately 60 percent of Māori students gained numeracy and literacy credits.

By the standards of Māori it is acknowledged that improvements can still be made in bilingual and immersion learning sectors. However, it is a great indicator that the problem does not lie with Māori students. They can and do achieve academically and in the domains of Pākehā curricula. Again, we need to look at the system of teaching in mainstream schools and ask what is lacking in the schooling process that fails to engage many Māori. 


\section{Summary}

International and national education tests and comparisons such as TIMSS, PISA, UNICEF League Table of Educational Disadvantage in Rich Nations, IALS, NEMP, and New Zealand's national qualification NCEA, clearly show gaps between the achievement of Māori and other ethnicities. Not only are these gaps persisting, despite a growing awareness amongst educators and policy-makers, in some cases they are getting worse. The UNICEF table in particular shows that New Zealand is one of the worst countries in the OECD for educational disadvantage in the lower end of the achievement scale. Other evidence shows a lack of engagement in mainstream education by Māori. This includes higher representations in the number of truants and student suspensions and low retention rates in secondary and higher education. However, positive results from Māori bilingual and immersion schools demonstrate the desire and ability of Māori students to learn and succeed academically. 


\title{
Chapter four: Review of the literature
}

\author{
Making the culture of the classroom inclusive of all students is a \\ delicate task that requires considerable knowledge and competence in \\ a multicultural society. Culturally responsive teachers know that \\ learning, whether in or out of school, occurs in a sociocultural \\ context...They are aware that cultural disjunctures between home and \\ school can make students appear academically incompetent, even \\ when the students actually know the subject matter well...Equally \\ important, they have knowledge of their students' cultures, especially \\ the discourse patterns and interaction styles valued in the children's \\ homes and communities (Villegas \& Lucas 2002: 109)
}

\section{Effective teaching for culturally diverse classrooms}

This section discusses the many theories that attempt to account for the educational inequality faced by Māori and other ethnic minorities around the world. It looks at literature from both here and abroad. Finally it presents the research currently used as a foundation for new policy by the Ministry of Education.

Flude (1974) offers four main explanations or groups of theory, for educational achievement gaps between different social groups.

1) Deficit theory: this accounts for a difference in achievement due to students' individual characteristics, for example lower I.Q., using 'inappropriate language' or being 'culturally deprived'.

2) Teacher expectation theories: these blame teacher attitudes and their resulting pedagogies, suggesting for example, that teachers are biased, racist or neglect girls in classroom interactions. 
3) School resource theories: blames the resources and practices of schools, for example, encouraging better response to the local community by encouraging more parental control over schooling (Nash 1993: 14).

4) Collective political empowerment theory: suggests that certain groups in society are disadvantaged because they are prevented from, or otherwise unable to, be fully involved in the economic and political realms, therefore denying them resources and progress in social institutions.

Deficit theory or 'deficiency orientation' focuses on what an individual believes people in a different group lack. These individuals usually compare ability and cultural resources that the other person has (Grant \& Sleeter 2007: 40). Deficiencies such as cultural, physiological and mental are identified according to the majority or mainstream societal norms. Bishop (2005) discusses the deficit theories of educationalists in New Zealand who, he says, locate the problem of Māori development and achievement with the learners. In explaining the gap in educational achievement for Māori, deficit theorists blame things such as conditions in the home (Lovegrove 1966) or cultural/ socio-economic background (Nash 1993). Hattie (2003: 7) compared the reading levels from asTTle data (www.asTTle.org.nz) and decile levels of schools, which are a socio-economic measure of the schools' communities. If socio-economic status was a factor in educational achievement, then the results should show an improvement for Māori in high decile schools. In fact, achievement gaps are still large between Māori and non-Māori at all decile levels, suggesting that it is not socio-economic factors that are important. Nechyba et al (1999) also found that recent research tends to show that home environments have less causal effects on learning, than previously thought. 
Bishop et al (2003) found that a majority of teachers in their 'Te Kotahitanga' study blamed students, their family, or the education system/ structure for the gap in achievement. This deficit theorising by teachers has implications for their teaching in that they tend to have lower expectations of Māori students' abilities. This creates a self-fulfilling prophecy of failure (Bishop et al. 2003; Holmes 1987). Deficit theorising could also preclude some teachers from examining and improving their own teaching pedagogy. They may be unsure if they can help their students because of the perception that the reasons for lower achievement are beyond the teacher's control (Grant \& Sleeter 2007: 43). Deficit theorising ignores opportunity gaps such as access to high-quality teachers, a relevant curriculum and good school facilities. Deficit theories do not take into account the aspirations of the families for their children and the power imbalances caused by colonisation (Bishop et al. 2003)

An alternative to deficit theorising may be embracing the various cultural knowledges and experiences found in a culturally diverse classroom. The focus changes to look at what skills and knowledge all students bring to the classroom or by having a 'difference orientation' (Grant \& Sleeter 2007: 46). This type of theorising presumes that the main limitation on learning is inappropriate teaching. When students have a cultural background different to that of the school environment there are inevitable difficulties for example with language, communication and social expectations. Students with different cultural home lives may experience a type of culture shock every day they attend school and they may exhibit behaviours reflecting their frustrations. Teachers subscribing to deficit theory tend to interpret this behaviour negatively and as a deficiency. The alternative would be to ensure as much cultural consistency between the school and home. Teachers would have 
knowledge of and support the cultures of their students and maintain high expectations of every student (Grant \& Sleeter 2007: 47).

In a large and comprehensive project in Australia, Lingard (2002) studied the pedagogies and assessment practices of nearly 500 teachers and interviewed 3000 students, in Queensland's primary and secondary schools. Professor Bob Lingard is a sociologist of education who teaches courses on educational policy and educational reform, at the University of Sheffield. He is the author/ editor of 10 books on educational policy and learning and has written more than 100 journal articles and book chapters. Professor Lingard is also editor of the journal, Discourse: Studies in the Cultural Politics of Education. This project is important because it developed the ideas of 'productive pedagogies, productive assessment and productive leadership' that have been influential in ensuing education policy reforms in Queensland other schools in Australia. The research showed that the classroom teaching was the biggest factor in students' learning. The study also found teachers should raise their expectations of students and that they needed ongoing training and preparation in working with students of different cultural backgrounds. Teachers reported that they were committed to engaging with all students, but were not sure how to and wanted more professional development. They also thought they did not have enough time to talk with their colleagues and needed more non-contact periods to do further training.

'Sustaining School Improvement: ten primary schools' journeys' is a report on New Zealand primary schools who are making definite attempts at improving student learning over the last three to five years (Cameron, Mitchell, \& Wylie 2002). This was a significant piece of research because it identified factors critical in sustainable school improvement in New Zealand. The study confirmed the main role of high teacher expectations and professional development for school improvement. 
The research found that the schools showing changes in student achievement had a strong focus on changing student learning and an analytic culture amongst the staff. Successful schools also had a focus on raising teacher expectations of student achievement and proactively worked towards improving student learning and behaviour.

These projects lend significant weight to the theory that expectations of teachers influence the achievement of their students.

Some research has shown that school characteristics play a relatively minor role in the development of educational disadvantage (Bradley, Draca, Green, \& Leeves 2006). However, the same research acknowledges that teacher interaction with indigenous students and the appropriateness of the educational materials used do have an effect on educational attainment. While parental choices outside of the home may have some impact on achievement, e.g. choice of school and community (Nechyba, McEwan, \& Older-Aquilar 2007) recent research suggests that schools are not as much to blame as previously thought. Early educational data had a tendency to be correlational in nature and researchers quick to make conclusions that any observed correlations represented causal relationships. Recent studies have offered better statistical analysis of the data and throw a more positive light on the impact schools may have on achievement (Nechyba et al. 2007).

Walker (1991), Bishop (2005) and others suggest that New Zealand's education system and policies are based upon inequitable power relationships. They propose that the behaviours associated with subordination and domination in the classroom perpetuate the non-participation in education by many Māori youth. Looking at some of the history of New Zealand's education system may give some insight into current education statistics. 
In 1867 the Native Schools Act was used to establish native schools within each of the iwi districts. Māori had no control over the curriculum and use of the Māori language was actively discouraged (Walker 1991). In 1900, the Director of Education George Hogben, advocated the teaching of manual and technical subjects or 'hand-work' in native schools. He targeted the very successful Te Aute College and pressured them to change their curriculum to exclude traditionally academic subjects such as mathematics (Walker 1991: 6). William Bird, who was the native schools inspector around that time, felt that the purpose of Māori education was to fit the students for life among Māori. One of his aims was to discourage the interaction between Māori and European and to reduce the competition with Europeans in trade and commerce (Walker 1991: 6). Bird suggested that Māori nurses should only be given training if they agreed to only work amongst Māori. He promised to intervene if any Māori nurses applied to work at a European hospital. He also encouraged Hukarere School for Māori Girls to change their curriculum so that subjects such as latin were replaced with needlework, cooking and domestic work. The girls would be taught to be 'good wives and mothers' (Appendices to the Journals of the House of Representatives, 1906 in Walker, 1991: 6). In 1931 T.B. Strong, Director of Education, contended that Māori education should turn boys into farmers and girls into farmers wives (Simon 1990: 110). These ideas and practices were reinforced in native schools by teachers having low expectations of their students. School inspections and a grading system also kept the teachers in-line with the policy of the Education Department (Simon 1990: 115).

Walker (1991) suggests that a two-tiered system was purposely and officially developed, where Māori were denied access to empowering education and their talents suppressed. This explains a 50 year gap between the first wave of Māori 
university graduates in the early 1900s and the second wave in the 60s and 70s.

"This institutionalisation of racism within the department and schools explains the existence and entrenched nature of the education gap between Māori and Pākehā” (Walker 1991: 7).

New Zealand's colonial history clearly has a strong and very real impact on our society today. How much colonisation and its processes have influenced the country's psyche may need addressing. Do teachers and their teaching practices reflect any of the ideals and values supported by the government so many years ago? To what extent do the values and practices of the colonising government influence our schools today? The focus of this research assumes that the answer to these questions lies in the education system. It aims to show that education in New Zealand continues to reflect the policies of the government and the lack of political empowerment of minorities in New Zealand.

Considering the many theories and possible reasons for disparities in achievement, the literature highlights the need for research that takes into account the diversity of classrooms. For as Nechyba et al (1999) note, educational research is becoming more reflective of the complicated nature of learning and child development. Broad trends are no longer valid. Recent studies tend to be more methodologically sound and more prepared to offer 'modest' results. The focus is now on trying to find smaller, more consistent and reliably estimated effects. In describing population trends in the United States, Pallas, Natriello and McDill (1989) suggest that educational achievement is influenced by formal schooling, family and community: "students who are educationally disadvantaged have been exposed to inappropriate educational experiences in at least one of these three institutional domains" (16). 
In particular Pallas (et al) identified five key factors relevant to education in the United States that are correlated with poor achievement. These are minority group ethnicity, low socio-economic status, single-parent up-bringing, education levels of the mother and coming from a non-English speaking background. Of these factors they suggest ethnicity as being the most widely recognised influence on educational disadvantage (1989: 17). Some international studies have found that minorities such as Hawaiian, Jamaican and African-American have failed in the classroom, not due to their language use (or pidgin dialects), but because they are often excluded in a number of ways from the classroom experiences and from the educational process in general (Siegel 2007: 66). These studies suggested that where a standard or majority language, such as English, is used as the only acceptable language in the classroom, problems arise. Negative attitudes of teachers emerged towards students whose language was different to their own. Students had a negative self-image due to the denigration of their language and culture and repressed their self-expression.

However, some researchers suggest that there is too much emphasis on the effects teachers have on students' learning (Nash \& Prochnow 2004) and argue against the current thinking that teachers are largely responsible for the disparities in educational achievement. They suggest that education policy is currently shaped by government officials, academics and journalists who promote the ideas that:

1. disparities can be reduced by raising teacher expectations

2. the effects of home resources and family practices on social and cultural differences are irrelevant and 'deficit theories' 
They argue that the evidence for teachers influencing achievement is overstated and that ignoring the home environment is 'misguided' (Nash \& Prochnow 2004: 176).

In a wide review of international literature Nechyba, McEwan and OlderAquila (1999: 5) found that most educational research suggests that genetics plays an important role and makes up about 50 percent of the difference in cognitive ability and school achievement. They also found that the student's environment was equally important such as influences from the home, neighbourhoods, schools and community groups.

Literature based on New Zealand educational achievement offers a wide range of factors influencing educational achievement. These factors also come from many areas such as the student, family, school and staff (Else 1997; John Hattie 2003). What is difficult to find is literature that agrees on the relative importance of each factor and most literature does not say how the factors or barriers worked or what to do about them.

John Hattie (2003) suggested that students make up about 50 percent of the variables in achievement and that they are a good predictor for success given the correlation between ability and achievement. Teachers and the way they teach account for 30 percent of variables. Hattie suggests then, that the focus should be on teachers and the way that they teach, as the factor that can be improved and that has the largest potential for change in education (J Hattie 2003: 4).

However, Nash and Prochow (2004: 178) suggest it is unusual to find a 50 percent variance in educational research and that it is difficult to confirm Hattie's figures due to a disparity between references. They caution using Hattie's data as there appears to be a lack of method and scarcity of details on the syntheses of the meta-analysis. They argue that a) Hattie's models underestimate the social class 
effects because the effects of intelligence are treated as an individual characteristic and b) Hattie overestimates the effects of the teacher because his data is taken from studies of innovations in teaching (2004: 178). In an analysis of international reading ability data, they suggest there is a relationship between household income, literacy resources and achievement and that teacher effects added relatively little to the overall variance in achievement (182). Nash \& Prochnow (186) also quote evidence that in general New Zealand students are happy with their schooling and teachers in particular at low decile schools and that this does not support the idea that teachers at low decile schools have low expectations of their students.

It is difficult to find a clear consensus in New Zealand and internationally on the causes of disparity in educational achievement. Classrooms are so diverse, perhaps it is never going to be appropriate to find one main effect on learning. It is important for this research to understand the direction New Zealand's education policy is headed and the reasoning behind this. Dr Adrienne Alton-Lee has carried out extensive research on education and is the chief education adviser for the Ministry of Education's Iterative Best Evidence Synthesis (BES) Programme. Her role is to strengthen the evidence-base informing policy and practice in education and to provide medium term strategic advice to government. She has published in a range of leading educational journals including the Harvard Educational Review and is author of the Ministry of Education's 'Quality teaching for diverse students in schooling: Best evidence $\quad$ synthesis' (www.minedu.govt.nz/goto/bestevidencesynthesis). In an overview of international and national studies, Alton-Lee (2003) found that quality teaching was the biggest factor influencing student achievement. She found that teaching accounted for 
sixteen to sixty percent of the difference in student achievement and that schools accounted for zero to twenty-one percent.

\footnotetext{
It is likely that the basic infrastructure of education contributes a great deal to the shared achievement that students gain, but the variance between individuals and groups, which is so substantial in New Zealand achievement results, is greatly influenced by how individual teachers teach. (Alton-Lee, 2003)
}

However, she stresses that this does not lessen the effect of other factors such as good leadership, employing highly qualified, capable teachers, providing teachers with necessary resources and encouraging school-wide development. It does give an area to focus our attention on and provides perspective on the impact that quality teaching has on achievement. Learning is a holistic experience, it does not only occur in the classroom. It is therefore important for the current research to look at what is occurring in New Zealand society that may affect Māori, particularly in terms of language use. 


\section{Language use in New Zealand}

Language, like other instruments that humans have at their disposal, has an infinite potential for good or evil. We can use language to cement relations with other people or employ it to wound, belittle and offend; we can use language to encourage others to develop their personality and individuality or we can employ it as means of domination and control (Watts 1989: 43)

The majority of New Zealand population is currently made up of those of European descent, a statistic which is changing. There are many reasons for this including immigration, birth and death rates. Ethnic proportions for under 18 year olds are changing even faster, which is of importance for those in secondary education in particular (Ministry of Statistics 2006). Bishop and Glynn (1999: 43) suggest that among this European majority bilingualism is rare, due to the political and economic colonisation of New Zealand, by English-speaking Europeans. This monolingualism of New Zealand society has had a negative affect on language learning and language attitudes, over the past few decades. When New Zealanders do take language study, it is mainly for functional reasons such as perceived benefits in economics or trade. Other reasons such as for personal enjoyment, intellectual stimulation, improving cultural understanding or language and culture maintenance, are difficult to encourage (Bishop \& Glynn 1999: 44). In contrast approximately half the worlds population is at least bilingual (Holmes 1987: 8). Research suggests that people who are bilingual enjoy many advantages, such as a better understanding of different cultures, flexibility in their thought, tolerance of cultural and linguistic difference and greater ability to manipulate their language (Holmes 1982: 11). 
Fortunately, 2001 census statistics did show an increase in people who could speak more than one language. Since 1996 this number had increased by 20 percent, with one in six New Zealanders being multilingual. English is the language spoken by most New Zealanders, although one in 50 did not speak English at all. After English, the most common spoken languages were Māori, Samoan, French, Yue (Cantonese) and German (Ministry of Statistics 2001). Table 2.1 compares the types of language speakers in New Zealand.

Table 2.1: Percentage of population for types of language speakers in New Zealand (Ministry of Statistics 2001)

\begin{tabular}{|l|r|}
\hline \multicolumn{1}{|c|}{ Type of speaker } & Percentage of population \\
\hline Monolingual & 83.9 \\
\hline Bilingual & 13.4 \\
\hline Multilingual & 2.7 \\
\hline
\end{tabular}

Within our population of over four million New Zealand becomes more multicultural every year (Ministry of Statistics 2006). There have also been regular increases in minority ethnic immigrants, as shown in Table 2.2. This means that educators need different skills and resources in order to provide a tailored curriculum that reflects the diverse backgrounds of students today. 
Table 2.2: Percentage (rounded) of ethnic groups within New Zealand 'usually resident' population totals for 2001 and 2006 Census

\begin{tabular}{|l|r|r|}
\hline \multicolumn{1}{|c|}{ Ethnic group } & \multicolumn{1}{c|}{2001} & 2006 \\
\hline European & 80 & 68 \\
\hline Māori & 15 & 15 \\
\hline $\begin{array}{l}\text { Other (inc. New } \\
\text { Zealander) }\end{array}$ & 11 \\
\hline Asian & 7 & 9 \\
\hline Pacific peoples & 6 & 7 \\
\hline $\begin{array}{l}\text { Other (inc. Middle } \\
\text { Eastern, Latin American } \\
\text { and African - MELAA) }\end{array}$ & No data & 1 \\
\hline
\end{tabular}

This change in the demographic make-up of New Zealand has had an effect on our schools. Many teachers today are working within classrooms very different to the ones they trained in. Schools in the future are likely to be even more multicultural. Teachers are going to need more support and training to teach culturallydiverse students, and a better understanding of how their pedagogies are influenced by their own culture. Of particular concern for this research is how much the way language is used by a teacher can influence the learning of their students.

According to Cooper and Fishman (1974: 6) there are generally four types of attitude towards language; attitude to a particular language (e.g. te reo Māori), to a feature of a language (e.g. to an accent or variation), to the way or context in which the language is used (e.g. for traditional marae protocols) and to the language as a cultural indicator (e.g. te reo as the language of Māori people). This suggests that attitudes towards a language cannot be separated from attitudes towards those who speak it. Due to the strong link between language and group identity, a lack of 
concern with a language (as perhaps reflected in poor pronunciation for example) suggests a lack of concern for its speakers (Deverson \& Gordon 1989: 52).

Tajfel (1981) studied two groups of children, from the United Kingdom and Israel. It was found that the children evaluated national and ethnic groups that were different from their own or 'out-groups'. This occurred without the children having had any real previous knowledge of, or contact with, these groups from which to base their evaluations. This suggested that children are: "highly sensitive to the socially-prevailing evaluations of national and ethnic groups" and that they are very susceptible to the attitudes and value systems of their societies (Tajfel 1981: 206). It therefore appears to be important to promote awareness about a language and provide accurate information to the public about a language, language learning and bilingualism, so that parents can make informed choices about their children's education (Waite 1992: 5). It also highlights the need for positive learning environments at an early age. Schools are a good place to encourage modelling of positive attitudes towards other cultures and languages. Janet Holmes considers the reasons for academic under-achievement in New Zealand. She suggests an important factor is the attitudes and expectations of teachers, parents, pupils and society, towards the child and their language.

If we dislike their accent, regard their home dialect or language as inadequate or as an educational liability, or if we have low expectations of children from a particular social or ethnic group, then it is all too likely that the children will perform in a way which reflects our negative attitudes and fulfils our low expectations (Holmes 1982: 
Children who are bilingual or second language learners are quick to perceive that a teacher's attitude to their language is the same as the teacher's attitude to the child and their family. They may react to perceived negative attitudes by being unresponsive and silent. However, if their language is seen to be valued, and regarded positively by their teacher, the students are more likely to be relaxed and co-operative (Holmes 1982: 27). In discussing sexist language Holmes (1982) also notes that the way in which language is used can transmit attitudes to future generations. "Language not only reflects the attitudes and stereotypes of the community which uses it, but also maintains and transmits those attitudes" (26).

The impact of colonisation on the Māori language is still felt today, despite it being an officially recognised language. Benton (1987: 72) suggests that recognising Māori as a national language does not disadvantage any New Zealander of a different ethnic background, Pākehā or otherwise. Promoting a community of acceptance and encouragement of bilingualism helps all minority cultures maintain their language and counter the tendency for many New Zealanders to be suspicious of 'foreign' languages and bilingualism in general. There are many other good reasons for encouraging the use and learning of other languages, particularly for children and youth. Maintaining and promoting any minority language can help to establish a strong sense of identity in minority children. Knowing where one comes from and having access to their own language learning helps build self-confidence and positive attitudes (Waite 1992: 16). This provides further support for the current focus on Māori language use in classrooms. 


\section{A brief history of te reo Māori}

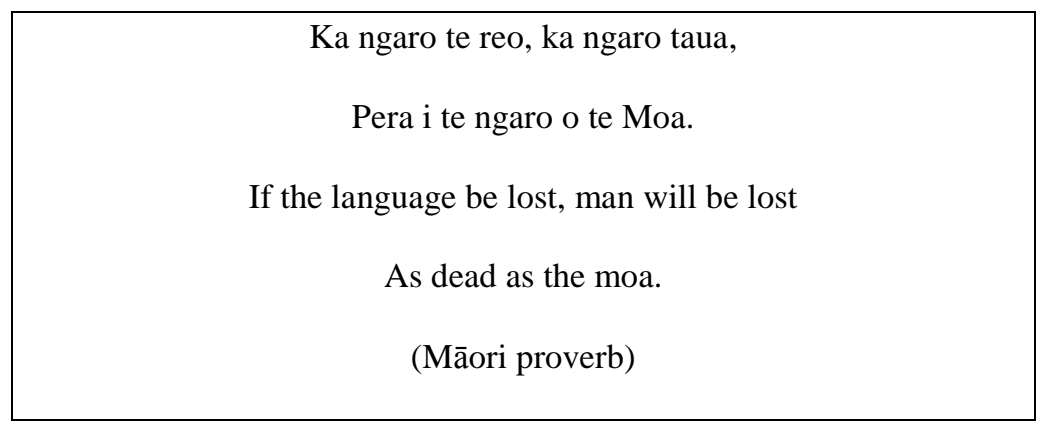

Over the past 200 years the Māori language has had a turbulent history. At the start of the nineteenth century te reo Māori was the main language spoken in New Zealand. However, as more English speaking immigrants arrived and schools established, the Māori language became less commonly used. By the mid-twentieth century there was a real danger of the language dying out. However, Māori initiatives in the 1970s and 80 s saw a revival of the language. Today over 130,000 people can speak or understand te reo.

The Māori language came very close to extinction during the twentieth century. Pākehā had become a majority in the population and English the dominant language. Māori was officially discouraged in schools and general society. Children were taught in English and often punished physically if they spoke te reo. During the 1940 s to 1970 s there was a mass migration from rural to urban areas. It was common for Māori parents to stop speaking te reo to their children, as they saw English language being a way of gaining better standards of living and wealth. For many reasons the Māori language was mainly used by some adults on the marae or for religious activities, and was rarely taught to, or used by, children (Te Puni Kokiri \& Te Taura Whiri i Te Reo Māori 2003: 13). However, Māori eventually realised that abandoning the language over the previous decades, either by choice or by force, 
had not resulted in the benefits promoted by Pākehā. Their children, who spoke English, were still leaving school with little or no qualifications (Benton 1987: 67).

During the 1970s kaupapa Māori initiated education programmes such as Te Kohanga Reo, Te Ātaarangi, and Kura Kaupapa Māori, were established. The 1980s saw the focus shift to media as well, and the sharing of responsibility for language revival among various government departments. In 1986 the Waitangi Tribunal reported their findings on the te reo Māori claim. They made five recommendations concerning; a) the use of te reo in court and other public or government dealings b) a supervising body to be established to monitor and support the language c) changes in educational policy regarding study of te reo d) formulation of broadcasting policy and e) change to state services employment conditions to encourage bilingualism. In the Māori Language Act of 1987, te reo was made an official language of New Zealand, a commission for Māori language was established and Māori speakers now had a right to use te reo during court proceedings (Te Taurā Whiri i Te Reo Māori 2003). The late 1990s saw the emergence of more community and iwi based language development and recovery programmes (Te Puni Kokiri \& Te Taura Whiri i Te Reo Māori 2003).

The 2006 Census showed that the population of te reo speakers has increased since 2001, but not in great numbers. Just over 130,000 Māori indicated they could carry out a basic conversation in te reo, an increase of 1128 people. However, only a quarter of the 15 to 65 age group are able to have a conversation in Māori (Ministry of Statistics 2006).

Te Puni Kōkiri has carried out many studies on the state of the language including; survey of attitudes, values, beliefs towards the Māori language (2002), 
survey of the health of the Māori language (2001), Māori language in the community (2004) and the Māori language survey (2007).

The survey of Māori and non-Māori attitudes toward the Māori language was particularly interesting. For Māori, it found that overall attitudes were positive and that most Māori value the language and were committed to the idea of learning and using te reo. Approximately 30 percent of Māori had some language skills or were learning. Māori were found to have an optimistic outlook on the language and thought that positive and significant gains had recently been made regarding the learning and use of te reo (Te Puni Kōkiri 2002).

For non-Māori, it was found that most recognised the value of the language, for Māori people. They also believed there had been recent improvements in the learning and use of te reo. However, the survey showed that non-Māori had little knowledge of the language and culture and 89 percent of respondents had no desire to learn. It was also found that within non-Māori there were a wide range of views regarding the use of te reo in public situations, with 90 percent of the opinion that Māori language use should be confined to the marae or the home (Te Puni Kōkiri 2002).

Positive gains have been made towards revitalising the language, as demonstrated recently in the Māori language survey (Te Puni Kōkiri 2007). This survey showed significant increases in the numbers of adults who can speak, read and write te reo. Also, the language is being used more frequently in the home and community. This suggests improvement in the transmission of language between generations. 
The findings of initial surveys lead Te Puni Kōkiri to make some recommendations, based on the fifth objective of the Māori Language Strategy which was:

\author{
To foster among Māori and non-Māori positive attitudes towards and \\ accurate beliefs and positive values about, the Māori language so that \\ Māori-English bilingualism becomes a valued part of New Zealand \\ society (Te Puni Kōkiri \& Te Taura Whiri i Te Reo Māori)
}

In their report Te Puni Kōkiri concluded that different groups within Māori and nonMāori needed different types of information and support. Also, due to the demographic profiles of the groups, appropriate media should be used to provide information and support. In particular the following recommendations were made:

- There is a need to turn the positive attitudes of Māori into tangible action in support of the language

- Need to raise awareness among Māori about language revitalisation strategies and activities

- Need to provide basic accurate information about Māori language and culture to non-Māori

- Need to consider and encourage debate on the Māori language as a symbol of Māori identity or New Zealand identity as a whole

- Need to provide those people who have a positive attitude towards, but no desire to learn about te reo, ways of showing their support more actively (Te Puni Kōkiri 2002: 59) 
Again it seems clear that education providers offer an ideal forum for working towards these objectives. It also emphasises the important role educators have in fostering positive attitudes towards Māori language. The Māori language commission recognises the important position teachers have in providing role models for children, encouraging the teachers to show children the value of the Mâori language and to promote positive attitudes towards "our indigenous language". The commission suggests ways in which teachers can do this such as giving children accurate and up-to-date information about the language, and by providing an environment where open discussion about the Māori language is encouraged. Other suggestions include using Māori vocabulary in the classroom and encouraging correct pronunciation of Māori names and words (Te Taura Whiri i Te Reo Māori 2003).

In New Zealand there is a very wide range of speakers using correct and incorrect pronunciation of te reo. Traditionally the attitude of many New Zealanders has been to look at Māori language as inferior and as such the correct pronunciation of it was not important (Deverson \& Gordon 1989: 52). The link between language and group identity, as previously mentioned, suggests then that the correct pronunciation of te reo Māori is an important indicator of respect for the Māori world. Despite this, and other good moral arguments for using Māori language correctly, many New Zealanders continue not to. However, it is important to acknowledge that many New Zealanders have a very positive attitude towards the Māori language and culture. The reason for relatively poor pronunciation cannot simply be blamed on mind-sets. Other things such as environment, family, friends and education all influence how te reo is used. "The naturalisation...of words from other languages is a universal phenomenon and is not in itself evidence of intentional 
maltreatment of the language the words are taken from" (Deverson \& Gordon 1989: $53)$.

The literature indicates that although the Māori language is stable and people are generally positive about it, much work is still needed to ensure it continues to get stronger. The number of native speakers needs to increase and they need more institutional support, for example in education, broadcasting, law and government. There also needs to be more domains and places where Māori is used (Waite 1992: $30)$.

\section{Media and Māori language}

Kia tupato e te iwi kei wehewehetia tatou te iwi Māori e nga pouaka
whakāta me nga mahi reo irirangi
As a people we should be aware of the divisive influence of television and
radio.
Rt Rev Whakahuihui Vercoe, the late Bishop of Aotearoa (in Williams
1987: 100).

The importance of radio and television in supporting Māori language and culture, cannot be underestimated (Williams 1987). In 1985 the Māori economic development commission report on Māori broadcasting held a very dim view of New Zealand media and stated that "The media in New Zealand reflects Māori people as a violent subculture of New Zealand society seen as rapists, thieves and murderers, save in war and sport" (Williams, 1987).

Advertising was also blamed for influencing the attitudes of young people towards Māori language and 'being Māori'. In a study of 12 year olds in Auckland, Vaughn and Hill found that they preferred not to be identified as Māori (Williams 1987: 102). Their research blamed media such as radio and television for this 
negative influence on the attitudes of the Auckland teenagers. They suggested there was a negative portrayal of Māori as actors, and a lack of 'front' announcers or positive role models in advertising. Kaumātua Henare Tuwhangai from Waikato, at the Kaumātua hui in 1982, also condemned radio broadcasters for their continued mispronunciation of te reo. Williams quotes an incident between the then Minister of broadcasting and Matiu Te Hau, a well-known teacher, educationalist and community leader. Mr Te Hau was asked by the Minister, on the topic of te reo pronunciation: "What does it matter?" Te Hau replied: "Some people call me Teehow and others Tayhaoo. My name is Te Hau. Now then, in reply to Mr Adam Sneeder, er Adam Snoyder, er Adam Sneezer, oh well - what does it matter?" (Williams 1987: 102). Twenty years later and the state of language use by various media is still questionable. News, sports, radio and other commentators demonstrate varying levels of correct and incorrect pronunciation and frequency of te reo use. However, one success is the introduction of a Māori television channel, offering a wide range of programming and plenty of opportunities to hear and practice correct Māori language use. If Māori language is to be valued by all New Zealanders then media will play a huge role in promoting the correct use. 


\section{Initiatives for improving Māori achievement}

There have been several projects recently which have aimed to raise the achievement of Māori students such as; Te Mana Kōrero, Te Hiringa I te Māhara, AIMHI, Te Kotahitanga, Te Kauhua/ Māori in Mainstream Pilot Project, Parent Mentoring Initiative (PMI), Whaia te iti Kahurangi: NZ Council for educational Research Evaluation (NZCER), Whakaaro Matauranga, Nga Taumatua - Research on literacy practices and te reo development, and Te Toi Huarewa.

Te Tere Auraki in the Ministry of Education uses the wider development of evidenced-based frameworks that explore and identify the key requirements of quality teaching for diverse students. This research and professional development strategy is focused on improving teaching and learning for Māori students, to improve academic and social outcomes in mainstream schools. The four independent but overlapping professional development strands of work that are coordinated by the strategy are:

- Te Mana Kōrero: professional development packages and workshops facilitated through 'School Support Services'

- Te Kotahitanga: Year nine and ten research and professional development project

- Te Kauhua: Māori in mainstream professional development project

- Te Hiringa i te Mahara: developing Māori secondary teacher capability and addressing workload.

The following sections summarise these projects that have supported Māori in mainstream education in Te Tere Auraki.

Te Mana Kōrero is a professional development series created by the Ministry of Education's Te Tere Auraki team. It works in conjunction with a wider 
information campaign that includes television advertising and aims to raise the expectations of educational achievement among Māori, the education providers and the community. Its main focus is on the belief that Māori can and do achieve and encourages high expectations of this. It uses research-based evidence to help teachers develop effective pedagogies, with the underlying premise that professional development makes a major contribution to teachers and their ability to make a difference for Māori students. Finally, it encourages strong, effective and respectful relationships between family, school and community, as these are seen to be extremely important in raising Māori student achievement. 'Te Mana Korero Relationships for Learning' is the third professional development multimedia package in the Te Mana series to promote effective teaching. The first included a video on raising teacher awareness on the need for high expectations of their students, and the importance of engaging their Māori students. The second video looks at how effective professional development can help teachers make a difference for Māori students and the third 'Relationships for Learning' looks at ways of developing relationships with whānau. It has used evidence from Te Kotahitanga and Te Kauhua, about what works for Māori students. This professional development package also reflects a key approach of the draft strategy for Māori education 'Ka Hikitia - Managing for Success'.

Te Kotahitanga Project started in 2001, funded by the Ministry of Education. It focussed on Māori students in four mainstream secondary schools, and asked what they thought about their education and ways of improving it. After an initial scoping report, the project had three stages; collecting and analysing experiences of students, teachers/ staff and family, developing an 'effective teacher profile' and professional development programme and finally measuring the results of this programme when 
implemented in schools. Results from the scoping project suggested that the main influence on student achievement was the quality of in-class, face-to-face relationships between the student and their teacher (Bishop et al. 2003). Initially reports showed that Te Kotahitanga had resulted in improvements for Māori students in terms of literacy and numeracy, and that relationships between students and teachers had improved (Bishop, Berryman, Cavanagh, \& Teddy 2007). However, a recent independent report commissioned by the Post Primary Teachers Association suggests that the success claimed so far does not match the data presented (Openshaw 2007). An independent three year evaluation by Victoria University has been commissioned by the Ministry of Education. This will examine the success of Te Kotahitanga towards the goal of raising Māori student achievement. The final report will be available in February 2011.

Te Kauhua/ Māori in Mainstream Pilot Project (2001) aimed to improve the mainstream schooling experience for Māori students. It helped schools develop their own initiatives towards this aim, rather than trying to implement a 'one size fits all' programme. Teachers were encouraged to reflect on their teaching practice and to question their attitudes towards and beliefs about their Māori students. This resulted in some being able to change their deficit thinking. The relationship between student and teacher was again, found to be critical to student success. The dispositions of teachers to respond to students needs were examined in depth and three important factors emerged; caring about student success, valuing the culture and listening to students' views (Tuuta, Bradnam, Hynds, Higgins, \& Broughton 2004).

Te Hiringa $\mathrm{i}$ te Mahara (the power of the mind) is a national professional development programme funded by the Ministry of Education that targets Māori secondary school teachers with particular emphasis on te reo Māori teachers. The 
project began in June 1998, to address the stress associated with the excessive workload of Māori secondary school teachers. The tools, techniques, programmes, and resources provided through Te Hiringa $\mathrm{i}$ te Mahara in the form of professional development are ultimately aimed at significantly improving education outcomes for students (Ministry of Education 2004c).

\section{Teacher training and professionalism}

Auckland and Wellington teacher colleges first recognised the need for Māori language courses in the 1930s. In the 1960s Māori studies lecturers were appointed to all the teacher colleges. However, the study of Māori language and culture was still optional until 1981 when it became mandatory for some study to be undertaken (Kaa 1987: 58). The professional standards for secondary teachers provides criteria for quality teaching (New Zealand Post Primary Teachers Association 2004: 106). This document specifically states criteria for professional development regarding knowledge of the Treaty of Waitangi, as well as Māori language and culture, as shown in table 3.1 .

Table 3.1 Professional standards for secondary teachers (from the NZPPTA collective agreement handbook 2006)

\begin{tabular}{|c|c|c|c|}
\hline Dimension & Beginning teachers & Classroom teachers & $\begin{array}{l}\text { Experienced classroom } \\
\text { teachers }\end{array}$ \\
\hline $\begin{array}{l}\text { Professional } \\
\text { development }\end{array}$ & $\begin{array}{l}\text { Are receiving } \\
\text { professional support } \\
\text { and encouragement } \\
\text { to successfully: } \\
\text { - Participate in } \\
\text { available professional } \\
\text { development } \\
\text { opportunities } \\
\text { appropriate to } \\
\text { individual needs and }\end{array}$ & $\begin{array}{l}\text { Demonstrate a } \\
\text { commitment to their } \\
\text { own ongoing learning } \\
\text { Participate } \\
\text { individually and } \\
\text { collaboratively in } \\
\text { professional } \\
\text { development } \\
\text { activities }\end{array}$ & $\begin{array}{l}\text { Demonstrate a high level of } \\
\text { commitment to: } \\
\text { - Further developing their } \\
\text { own knowledge and skills } \\
\text { - Encouraging and } \\
\text { assisting colleagues in } \\
\text { professional development } \\
\text { - Further developing } \\
\text { understandings of the Treaty } \\
\text { of Waitangi }\end{array}$ \\
\hline
\end{tabular}




\begin{tabular}{|c|c|c|c|}
\hline & $\begin{array}{l}\text { school priorities } \\
\text { including } \\
\text { opportunities relating } \\
\text { to the Treaty of } \\
\text { Waitangi }\end{array}$ & $\begin{array}{l}\text { Continue to develop } \\
\text { understandings of the } \\
\text { Treaty of Waitangi }\end{array}$ & \\
\hline $\begin{array}{l}\text { Te reo me ona } \\
\text { tikanga }\end{array}$ & $\begin{array}{l}\text { Are expanding } \\
\text { knowledge and } \\
\text { developing sound } \\
\text { skills, with advice } \\
\text { and guidance in: } \\
\text { - Accurate } \\
\text { pronunciation of } \\
\text { basic Māori } \\
\text { vocabulary } \\
\text { - Common } \\
\text { greetings and waiata } \\
\text { - Basic Māori } \\
\text { protocols }\end{array}$ & $\begin{array}{l}\text { - Continue to } \\
\text { develop } \\
\text { understandings and } \\
\text { skills in the } \\
\text { appropriate usage and } \\
\text { accurate } \\
\text { pronunciation of Te } \\
\text { Reo Māori } \\
\text { - Demonstrate an } \\
\text { understanding of } \\
\text { basic Māori protocols } \\
\text { when opportunities } \\
\text { arise }\end{array}$ & $\begin{array}{l}\text { - Demonstrate } \\
\text { commitment to the } \\
\text { promotion in education of: } \\
\text { - The appropriate and } \\
\text { accurate use of Te Reo } \\
\text { Māori } \\
\text { - The adoption of Māori } \\
\text { protocols where appropriate }\end{array}$ \\
\hline
\end{tabular}

In March this year the first national curriculum for te reo Māori was launched. This provides a draft framework for teaching and learning of te reo Māori and tikanga in mainstream primary and secondary schools and should encourage wider use of the language in New Zealand. The curriculum guidelines were trialled in five regions in 2005 then revised and distributed to all schools for feedback in March 2007. The final version of the curriculum guidelines will be in schools mid 2008 (Ministry of Education 2007d).

The government has also developed the evidence-based policy document called 'Ka Hikitia - Managing for success: the draft Māori Education Strategy 2008-2012'. This is a reflection of the aims that the government has in terms of providing effective education for Māori students. One of its approaches to change is developing productive partnerships with Māori students, whānau and educators 
working together to produce better outcomes. Another of the main areas of focus is Māori language education. According to the strategy, Māori language is recognised as a treasure and aims to teach students the value of te reo. It addresses the issue of providing alternative learning options, building mātauranga and knowledge of tikanga Māori and developing quality language ability (Ministry of Education 2007c). If this strategy is to be implemented successfully, teachers in all schools will need relevant support and professional development in terms of Māori language.

A current initiative is attempting to address this issue called Te RITO (Te Reo Itinerant Teacher of Māori). Te RITO is a professional development programme that focuses on supporting quality teaching of te reo in all classrooms. It was created as part of a Ministry of Education and Northland iwi partnership called Te Pūtahitanga Mātauranga, and began several years ago in Te Taitokerau (the Far North) schools. Te Pūtahitanga Mātauranga (TPM) is an education improvement and development project aimed at raising Māori students' achievement in Te Taitokerau. Te RITO aims to improve the te reo writing and speaking skills of teachers and students in mainstream schools. The schools are supported with new practices in planning, teaching and assessment, and helped to bring the school and Māori communities closer. Results at many of the participating schools show that students are improving their ability in overall Māori language use, including vocabulary, sentence structure, comprehension and pronunciation. It also has affected some students' home lives, where parents have become more involved in learning at home and in the school. Students and teachers both reported feeling more comfortable in their communities, where a large proportion of the populations are Māori. 


\section{Summary}

There are many different schools of thought and theories used to explain the gap in educational achievement between certain groups. The main focus here and internationally seems to be on ethnic groups, in particular minorities. The theories tend to fall into five broad categories; deficit theory, teacher expectation theory, school resource theories, political empowerment theory and alternative theories. Many studies can be found to support and oppose each theory, and it is very difficult to pinpoint one particular cause for the disparity in educational achievement. In New Zealand the Ministry of Education policy trends have been influenced by the research and analysis of Dr Alton-Lee. She has found, in a wide overview of national and international studies, that quality teaching is the main factor influencing student achievement.

Literature on language use in New Zealand was also considered relevant for this research. With the majority of New Zealanders being Pākehā and mono-lingual, there is evidence that the use of and attitudes towards minority languages can have some negative affects on the native users of that language. The history of te reo Māori in particular has been turbulent, and the number of speakers of te reo had fallen dangerously over the past century. Today the number of speakers of te reo continues to grow, but it is still a language in need of protection and revival. The responsibility for this lies in many domains such as the media and education, with teachers playing an important role in the encouragement of te reo use by younger generations.

Currently in education there are many good initiatives in action, aiming to raise the achievement of Māori students. These include Ministry of Education funded projects such as Te Mana Kōrero, Te Kotahitanga, Te Kauhua, Te Hiringa i Te 
Mahara and Te RITO. These projects have all demonstrated positive results for Māori and share a focus on good teaching practices and professional development support for teachers. Teacher training and professionalism documents such as the Post Primary Teachers Association collective agreement, encourage the learning and development of knowledge in Māori language and tikanga. These standards are supported by the government policy document 'Ka Hikitia', the draft Māori education strategy, where there is strong focus on developing relationships with whānau and community, and acknowledging te reo Māori as a treasure to be utilised across all curricula.

Overall the literature is positive and shows a trend towards policy and initiatives that work for Māori, based on evidence and consultation with iwi. There was however a clear lack of literature focussed on the impact of Māori language use in schools and the wider community, and what effect this has had, and continues to have, on Māori people. 


\section{Chapter five: Presentation of findings}

This chapter presents the results for the two groups of participants - students and teachers. Results for students were collected in two ways - surveys and focus groups. Results for teachers were collected by surveys and interviews.

The student survey results are presented first. The focus group results are then given, and after this section there is an overall summary of the student results.

The teacher results begin with the survey answers and then the interviews. This section is also summarised at the end of the teacher results.

\section{Student surveys}

\section{Overview}

The survey results related mainly to te reo use in the classroom by teachers. Initial background information was gathered such as the students' year group, selfassessed language ability, whether or not they took Māori as a subject and reasons for this. Results showed that the majority of students thought te reo pronunciation was important. A smaller proportion of students thought that teachers in particular should use correct pronunciation, compared to the proportion of students who thought that all New Zealanders should use correct pronunciation. Significant proportions of teachers were thought to be regularly mispronouncing te reo, and the students in general agreed that te reo should be used in class. Reasons were provided to support this. A third of students also felt that it was not important to use te reo in class, and again many reasons were given to defend this opinion. Many suggestions were given for how te reo use by teachers could be improved. The most common ones were learning basic words, greetings and pronunciation, particularly of vowels, 
names and common place names. At the end of the survey students offered general comments regarding language use.

\section{Survey results}

Sixty-four students filled out a survey containing ten questions. This survey can be found in Appendix A. The students were from year nine to year thirteen classes. The smallest group was the senior or year 13 class. The rest of the students were fairly evenly distributed across the other year levels (see figure 1).

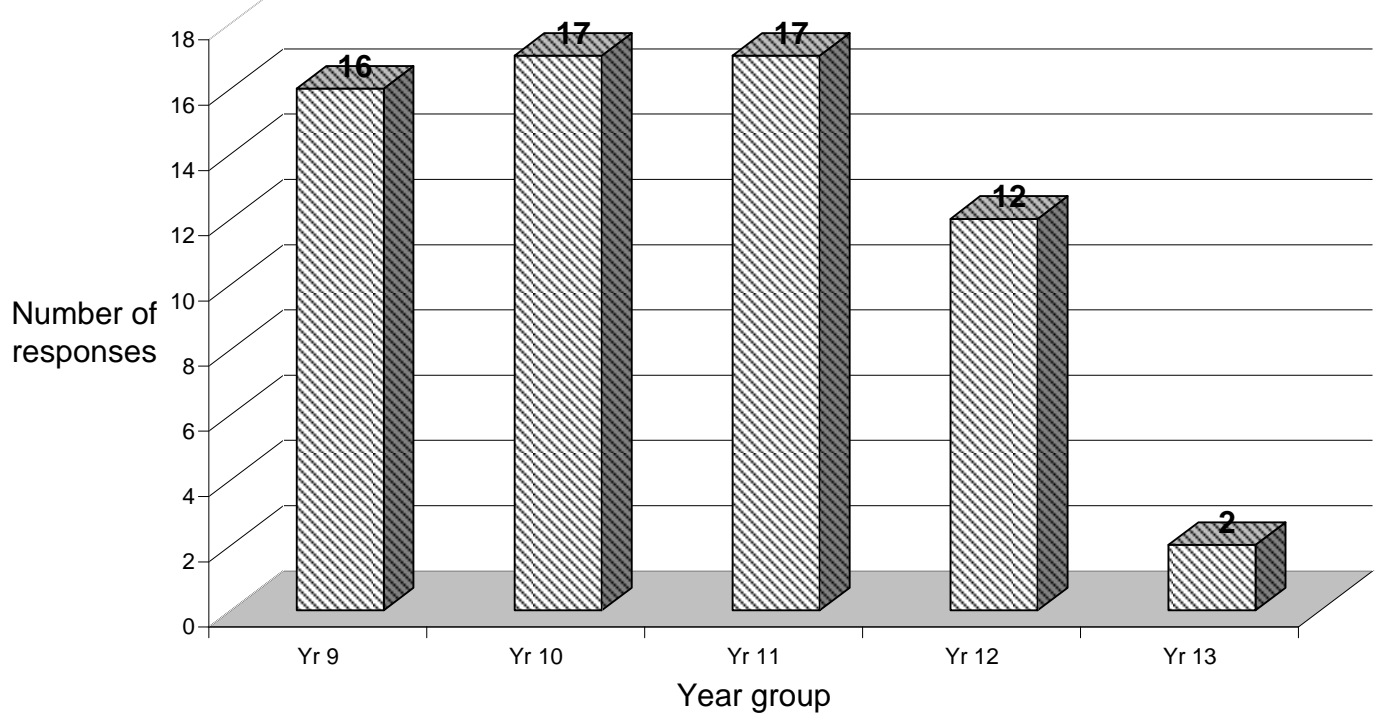

Figure 1. Students grouped by Year

Students rated their own Māori language ability and they all had at least some ability in speaking te reo (see figure 2). Over half the students felt they were at a beginner level. Twenty students responded that they were intermediate speakers. Six considered themselves to be fluent. 


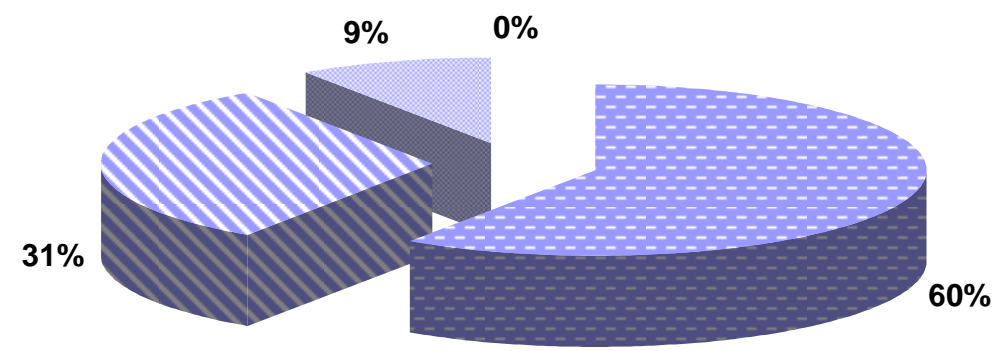

Don't speak it - Beginner

Intermediate

Fluent

\section{Figure 2. Students' self-assessed Māori language ability}

The majority of students studied Māori language at school. Only three percent did not, at the time of the survey, take it as a subject. One reason for not studying te reo was that the student wanted to focus on senior subjects related to their future career goals. Another reason was that the student did not know anyone else in the same year taking the subject, so was too shy to take the subject. They were unable to pick it up again the following year. There were two main reasons why students did study Māori language. The first was because they were Māori themselves and it was an important part of their culture and identity. The second was so they could improve their ability or gain fluency. The next most common reasons were that it was a fun, interesting and 'cool' subject to learn, and that it was important to learn more about Māori culture and whakapapa. Several students stated that it was important to them personally as they had studied or learnt it in some way, since they were young. Other reasons given were:

- It was the only subject available

- To show respect for the culture

- A parent encouraged them to

- $\quad$ They use the language daily

- It is part of New Zealand culture and an official language 
- To help keep the language alive

- They can use te reo in the class without embarrassment

The majority of respondents, 80 percent, thought that New Zealanders should be expected to pronounce Māori language correctly (see figure 3). Nine percent said that it did not matter or that New Zealanders should not be expected to pronounce it correctly.

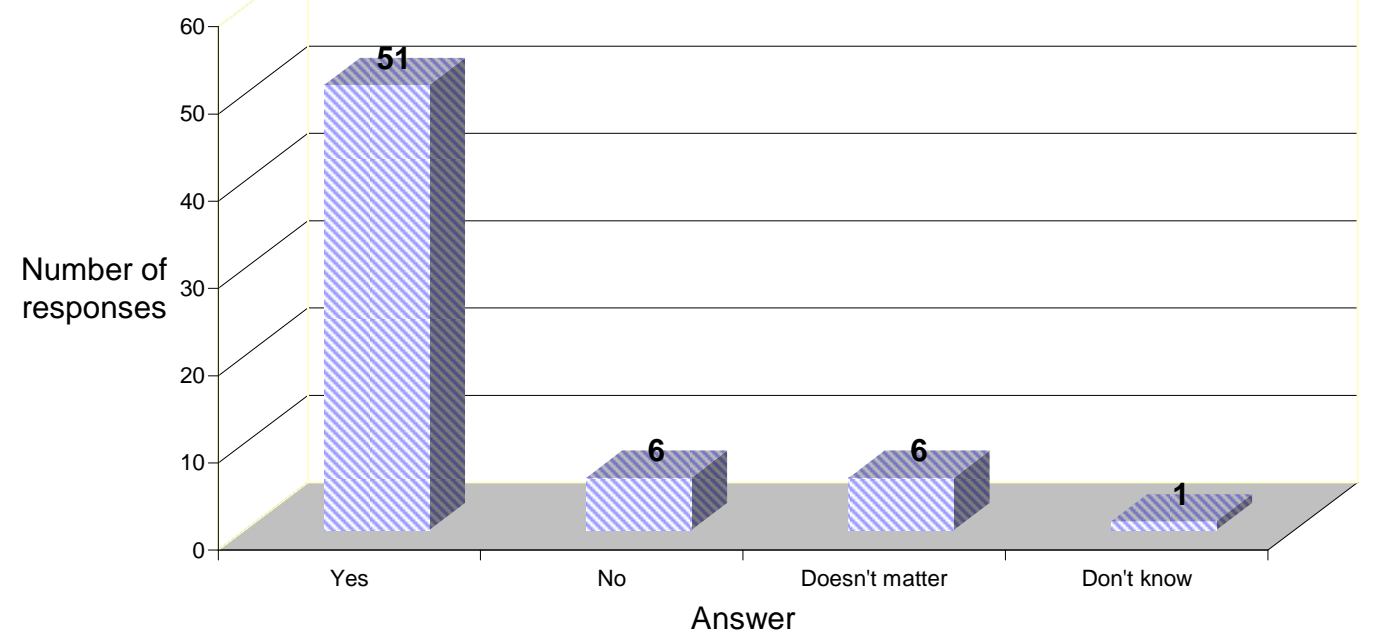

Figure 3. All New Zealanders should pronounce te reo correctly

Sixty-three percent of students said that teachers in particular should always pronounce te reo correctly (figure 4). Twenty-five percent thought that teachers should 'often' speak it correctly and nine percent indicated 'sometimes'. Three percent of students responded that teachers should 'never' be expected to pronounce te reo correctly. 


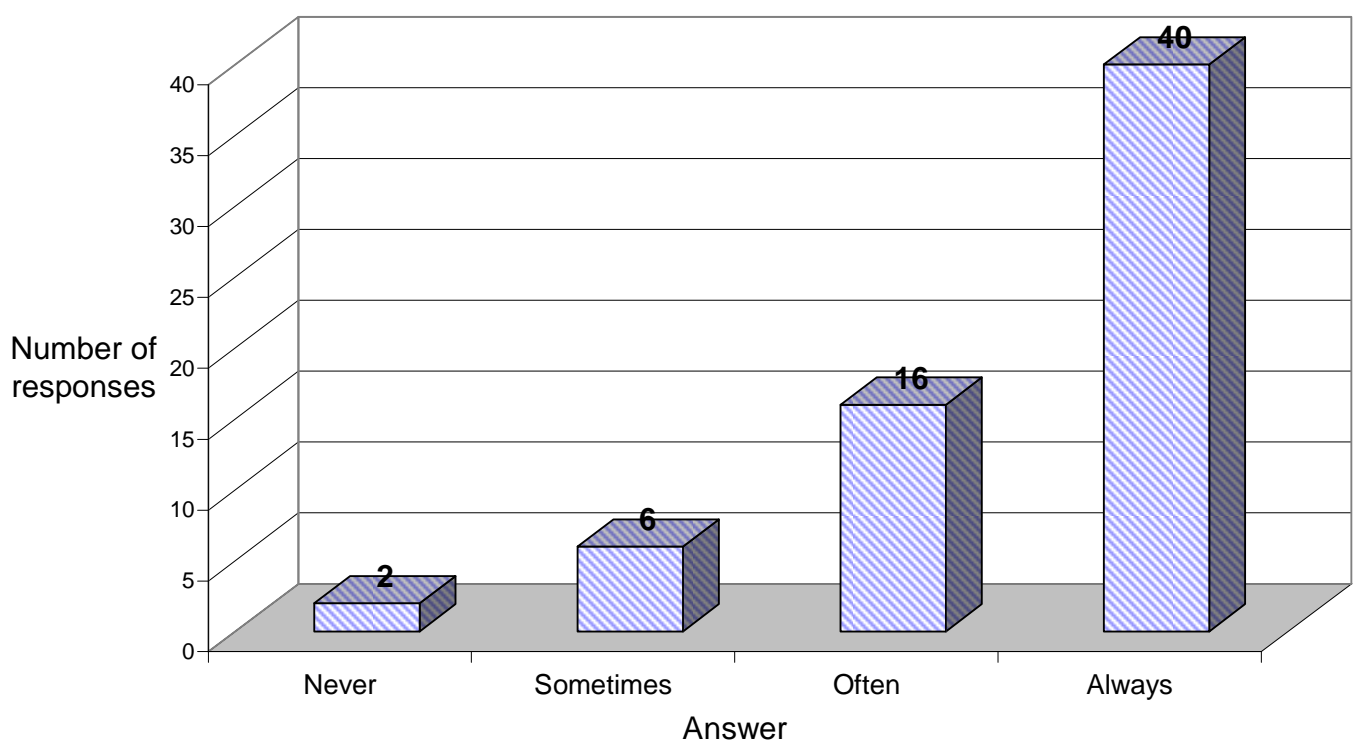

Figure 4. All teachers should pronounce te reo correctly

Most of the students, 95 percent, study with five or more different teachers during the school day. Thirty-nine percent of students thought that between one and three of their teachers mispronounced te reo (figure 5). Twenty-three percent indicated between four and six of their teachers, and six percent said over six of their teachers mispronounced te reo. One respondent thought that none of their teachers did. A relatively large number 30 percent, responded that they did not know how many teachers, if any, mispronounced te reo. 


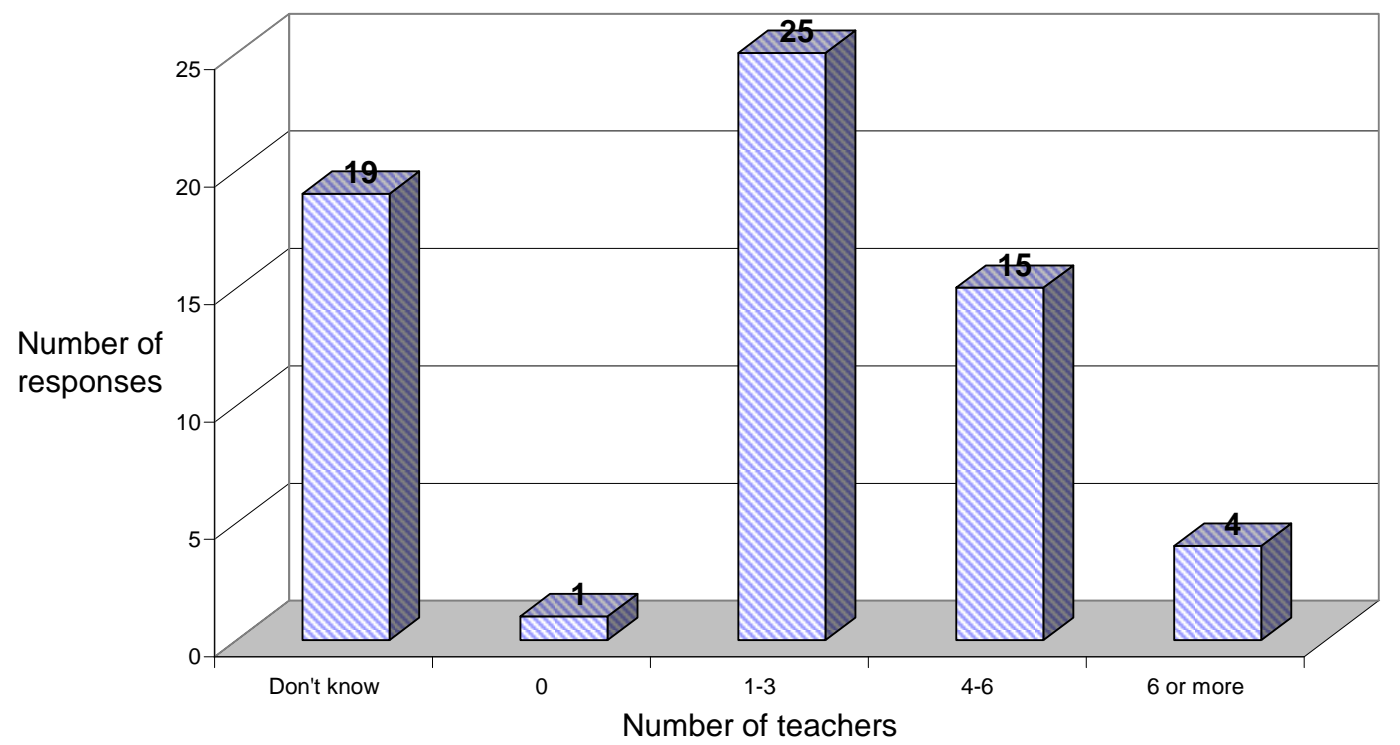

Figure 5. Number of the teachers judged to be mispronouncing te reo

Forty students thought that it was important for Māori language to be used in the classroom (see figure 6). The most common reason for wanting teachers to use te reo was due to it being an official language and native to New Zealand.

"In New Zealand it is important to use Māori in the classroom because this is the country it originated from and has significance to peoples' lives while they are here”

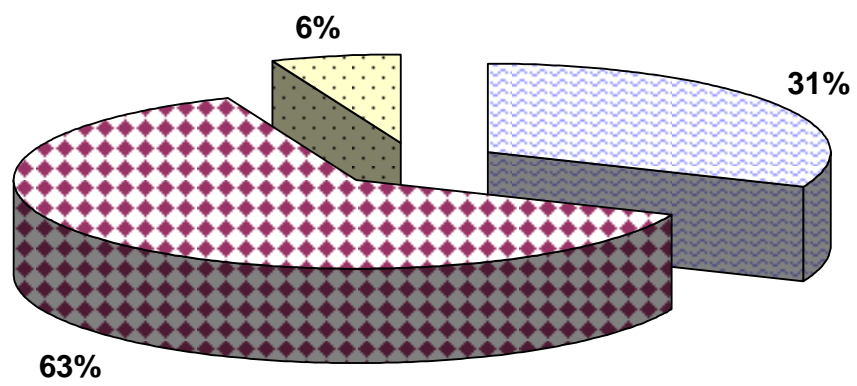

Figure 6. It is important for teachers to use Māori language in the classroom 
A significant number of students thought that it depended on the subject being taught and how relevant Māori language was in that subject. For example, many suggested that subjects such as science, English or other language classes, should not be expected to incorporate te reo in the lesson.

"If you are learning about New Zealand or are in a class that has something to do with the Māori culture then yes, but if you are learning about e.g. World War II, then no"

Seven students felt it was important to use the language as a means of acknowledging and respecting their Māori ancestors and to learn more about the culture.

"[Yes] because it's the language of this land, it's important to remember your ancestors and incorporating Māori daily is the way to go"

The same number also thought that using the language more often would help other people to learn, and improve their ability and understanding of te reo. Four students felt that using te reo showed a willingness to learn, and a respect of, the language. Other comments were made such as the students enjoyed communicating to their friends in te reo and that everyone should know basic Māori words and phrases. A couple of students stated that it was good to try to attempt correct pronunciation and that it was very nice to hear it spoken in different classrooms.

“It doesn't matter 100\% but if they say some Māori words every now and again it shows they know or if they try to pronounce something in Māori it shows they try or want to learn..." 
Twenty students responded that they did not think it was important and four students did not answer. Three main reasons were given for 'No' responses. One was that teachers and students have different levels of ability and not everyone can speak and understand te reo. Another was that the decision whether or not to speak te reo should be left up to the individual. Again, students felt that it also depended on the subject. Some subjects provided more opportunity in the curriculum to use te reo, than others. One student felt that because most of the work done uses English language, Māori was not needed. Another student said that Māori language should not be favoured over other languages, especially in a multi-cultural environment.

"[No] because we're living in a mixed language society and it's not fair to favour one language over the other"

Students were asked what advice they would give teachers on how to improve their use of te reo. Nearly half responded that it was important to learn basic words and greetings. They thought that teachers should concentrate on learning the vowels and correct pronunciation. Another common suggestion was to take up formal study and attend Māori language classes. Many students encouraged teachers to ask their peers or students for help when learning and to hear the correct pronunciations of words. Six students thought it was very important for teachers to learn the pronunciation of personal and place names. One student mentioned their hesitance in giving advice to teachers themselves, as they thought it would not be welcomed. Several other suggestions were offered:

- Use it more often at home and at school

- Listen to it spoken more often or to songs

- Label objects in the classroom with the Māori name

- Just try to speak Māori and have more confidence 
- Get a book of basic phrases to refer to

- Take opportunities to learn about the Māori culture in person e.g. marae visits

- Speak it with the correct pronunciation or not at all

At the end of the survey students were given the opportunity to write down any general comments they had about te reo. Many comments were recorded, and the four most common ones were (in no particular order):

- It is important to know and use te reo, but it is an individual's choice whether or not to

- Everyone should try to use it in some way

- Māori language should be used in every school in New Zealand

- Māori should be a compulsory subject in all schools because it is an official language 


\section{Student focus groups}

\section{Overview}

The focus groups started by negotiating questions that should be discussed. Students were able to provide several alternative questions to those presented by the researcher. Themes emerged around pronunciation and use of te reo. Other general issues arose such as improving the school environment to reflect Māori students' worlds, improving relationships between teachers and students, correct use and respect of Māori tikanga, and equality in classrooms and in the wider school environment. Students discussed, in depth, ways of improving or solving these issues, with the most common way being to improve language use; teachers making an effort to use te reo in class, and pronouncing student and place names correctly. The results of the focus groups are presented as a whole, not separated by school.

\section{Focus group results}

Firstly, students were invited to suggest appropriate questions for discussion. The following questions were offered by them:

- Do you know basic pronunciation?

- Do your teachers ask for help in pronouncing your name right?

- Should teachers speak te reo in the class?

- Should Māori be compulsory [as a subject]?

- Do you think Māori should be used in assemblies or other types of meetings?

- Should we be able to sit exams in Māori?

- Do your teachers use it [te reo] enough? 
- Do your classmates respect the language?

- Do the students value the teacher using te reo?

- Do people recognise or respect your feelings by pronouncing Māori correctly?

The students also agreed that the questions presented by the researcher were relevant and should also be presented to the focus groups. The discussion topics and content emerged around three main themes, which were related to language use and other issues as follows:

- Pronunciation of te reo

- General issues for students in the classroom

- Ways in which teachers could improve their use of te reo and/ or teaching of Māori students

\section{Pronunciation of te reo}

All of the students agreed that New Zealanders in general should pronounce te reo correctly. They felt it was important especially because it is the language of the indigenous people and an officially recognised language.

“...I think it is....because it shows that they respect our language”

“...and it's part of our culture really. It's part of the New Zealand way of life..."

All the students voiced their opinions on the attitudes and actions of the staff and students at their schools. Many students were angry or disappointed with perceived laziness from most of the staff by not trying to pronounce te reo correctly, 
and did not think it would change. They also acknowledged those teachers who did make an effort.

"I think laziness annoys me...when people just don't even bother to get things right...if you said 'water' quickly your tongue rolls and makes the ' $r$ ' sound ${ }^{\prime} . .$. people they can do it but they don't [try]"

Student A: I mean, like my teacher today she asked me how to say a word 'cause she knew she wasn't going to say it right and she said 'How do you say it right? I'm not going to say it properly' and it was good that...some of the teachers are actually trying. But when...some of the other [teachers] say it wrong and stuff... and that annoys me when they don't even try and correct themselves...they know they're wrong

Researcher: Have you ever corrected a teacher? What was their reaction to that?

Student A: I once corrected MrX and he just looked at me and kept on talking... he didn't say 'oh sorry'. But my new teacher Miss X she always says 'oh I'm sorry' and she says it right

Student B: Yeah, I've corrected heaps of teachers, mainly with my name...when it comes to my name all of them have apologised...because you know, it's my name! But when it comes to other things like just correcting place names, they acknowledge it but they still don't change...they keep saying the wrong thing

It was suggested by many students that people should make an effort and that while pronunciation was important, it was just as good to hear people trying.

“I think just as long as they show they're trying to pronounce it, not like say it [wrong] and then 'who cares?'”

\footnotetext{
${ }^{1}$ The ' $r$ ' in te reo is a rolling sound similar to the English ' $\mathrm{l}$ ' as the tongue flicks forward from the roof of the mouth e.g. the $r$ in 'Māori' sounds very similar to the 1 in 'mouldy'
} 
The students thought there were many different reasons for people in New Zealand mispronouncing te reo. All agreed that one of the biggest factors is a lack of knowledge and opportunities to learn the language. Some suggested that media plays an important part in influencing how people speak te reo. They thought that there exists too much incorrect role modelling of language pronunciation, by television and radio presenters.

\footnotetext{
"The way it's advertised...like the media, how the media pronounce

it...One News is pretty good, they'll say 'Pomarie'...but little things,

like when they do the weather 'Towpow' [instead of Taupo]... and I

don't know if that's out of ignorance, which I suppose is excusable or

if it's just laziness"
}

Some students commented that many New Zealanders just do not use the language correctly, because they do not need to. They saw it as a reflection of the attitudes of the speakers and demonstrated a lack of concern or care for the language. A few even went further and suggested mispronunciation of te reo was a form of racism towards Māori.

A large number of students agreed with a suggestion that hearing correct pronunciation depended on where you live and your community. They related this to the idea that some communities and families within them are not taught or expected to respect other languages and cultures.

\footnotetext{
"If you're not brought up with the language of [other cultures]...if you're not brought up with being taught to respect other languages and try to pronounce it then they're not ever going to try...not ever...but they just don't have the opportunity to pronounce it right and use it [te reo]"
} 


\section{Issues for students}

It was difficult to gauge the relative importance of the many issues that were raised during the course of the focus groups. Most of the time students agreed with the statements of their peers, and very rarely disagreed with any comments made. Agreement was often by nodding of their heads and verbal agreement. There were no issues raised that were clearly more important than others. The issues raised have been presented in general themes.

Many issues surrounded the school environment, including the classrooms and the school setup in terms of management and teachers. Students commented on feeling a sense of belonging in the Māori classrooms and they felt that different informal rules were observed there.

\footnotetext{
Student A: It's kinda weird how everyone knows this is the Māori class so they follow different rules in here than other classes...

Researcher: Why do you think they do that?

Student B: We care

Student C: Yeah, we care more than about other places...we're so separated from the rest of the school

Student B: We care that it's [the Māori teacher] that's told us to put our [uniform] right...

Student A: I think it's 'cause we have a sense of belonging in this class...that we look after it more...but [in the rest of the school] it's just another class
}

They had a greater respect for the Māori teachers, who encouraged correct Māori tikanga in their classroom. 
"I think honestly part of it is because [they are] Māori and acknowledges us for being Māori and makes sure that we do keep...Māori ways when we're around each other"

The Māori teacher was informally available in one school, as a mentor and counsellor to some students, where the students felt they could not talk to or even trust the school counsellor.

Student A: We have a closer relationship with [the Māori teacher] than we do with most of the other teachers

Researcher: Because they are Māori or the way they teach you or...? Student B: [They] put effort in... [they] help us

Researcher: In what kind of ways do they help you?

Student B: Just everything

Student $C$ : More than academic

Student B: [They are] like a counsellor...we do have our own counsel teacher but we just don't trust her...even though she says everything's confidential...she talks about it to other teachers in the staffroom...

Some students felt that their kapa haka group was only recognised by the staff and management when they needed them to carry out pōwhiri or other performances. Many students wanted to see more recognition of Māori student achievement within the schools, and were tired of only hearing the negative things Māori students did.

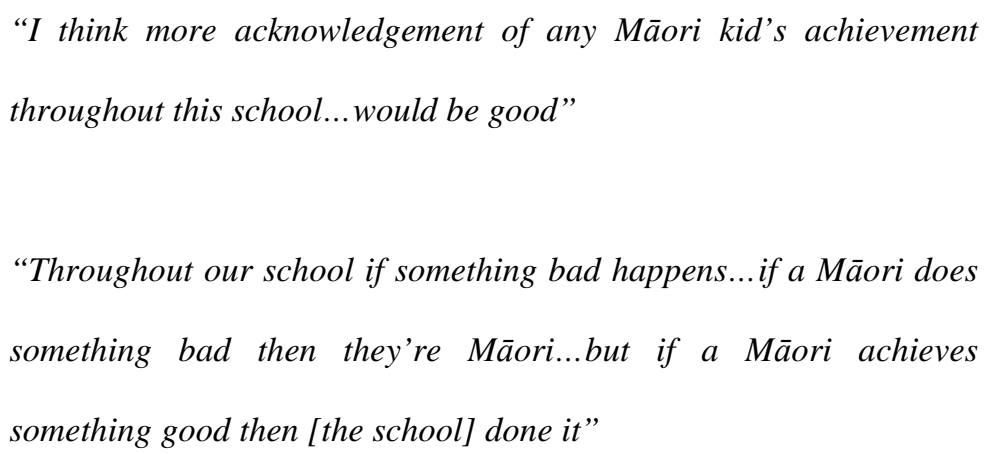


One group of students was very disappointed at the lack of Māori student leaders in their school and felt that they were discriminated against by not being allowed to fill official student leader positions. All students agreed with the suggestion that te reo was not a priority for their schools and used very rarely by teachers, because they were a minority in the student population.

Many students felt that tikanga was just as important as correct language use. They thought that teachers should show more respect for their culture and follow simple Māori protocols in the classroom.

\footnotetext{
"I think tikanga is more important than pronunciation...like sitting on the tables and that kind of thing. That goes on in my classrooms all the time...teachers do it a lot"
}

\begin{abstract}
"Once I told MrX to get off the desk...he was sitting on the desk...it was just one of these [student] desks not his desk...and I was 'Mr X get off the desk' and he was like 'Why?' and I [said] 'cause you eat off the desk' and he [said] 'Well that's not my culture,",
\end{abstract}

A few students suggested that school leaders, particularly the Principal should be good role models, use correct Māori pronunciation and use it more often. Other students reported experiencing negative responses from teachers, when they had absences for Māori focussed trips, or tangi.

\footnotetext{
Student A: We've got a [Māori] group and some of the teachers who aren't Māori don't want it because it's unfair 'cause only the Māori students get to join it. But they [teachers] are not doing anything to do with Māori [students] Researcher: How do you know those teachers feel like that?
} 
Student B: You can kind of see it too, can't you? [rest of group agrees] 'cause when you go away on trips they're like 'Oh why are you going away?' or 'Where were you?' and you tell them...and they're like 'Oh...'

Several thought that Māori should be a compulsory subject in all schools and that they should have the right to sit exams using Māori language. A few students had experienced what they perceived to be racism in the teaching and content of some subjects.

Student A: One of my teachers, we were doing a thing on stereotyping...and we saw a lot of negative videos on Māori youth, and she made it even worse, she made Māoris sound really bad and she didn't pronounce anything properly and I think she made the class feel a bit intimidated of me, because I'm the only Māori in that class

Researcher: You said that she made it worse?

Student A: 'cause it's [subject] so we are studying those kinds of clips, on what the media makes you think, but she kind of justified what the media was doing. 'This is not just the media's opinion but the right opinion'

All students agreed that in general, te reo should be used more in schools and classrooms. The majority felt it was good to hear it used, as it helps people to learn, but at both schools, small numbers of teachers are using te reo. For those teachers who were using it, students thought it important that they ensured everyone in the class understood what they were saying. The equal treatment of students in a classroom was considered very important by all participants. They suggested that 
there was a fine line between showing respect to different cultures (for example, by using their language) and embarrassing students by showing favouritism.

"Acknowledgement of our culture is nice but...special treatment for being Māori is a bit...over the top...kind of like singling me out"

There was a general perception amongst both groups that teachers and students often did not intentionally misuse or disrespect Māori language and culture. Students thought their peers didn't really care either way about the language. Although it was felt that the non-Māori students occasionally tease others or make fun of teachers using te reo, it did not happen that often. For teachers it was suggested that it was simply because they did not have the techniques to deal with Māori students as opposed to Pākehā or other cultures.

"I don't think they [teachers] have anything against us being Māori,

it's not like they're not supporting us. It's more the fact that they

don't know how to use different methods for us. I don't think they do.

I think it's just they teach [us] how they teach everyone else. It's not

a bad thing that they're not including te reo Māori”

\section{Ways teachers could improve}

When asked how they thought teachers could improve the way they use te reo, the students were keen to offer many suggestions. The most common ones related to three main areas; pronunciation and language use, tikanga and relationships, teaching and classroom/ school environment.

All students strongly believed that teachers should try using and pronouncing te reo correctly, and to demonstrate that they were at the least, making an effort. They thought it was important to get student names right and also place names. 
Student A: It's just good that they try, seeing them trying is quite good because it makes you feel as if te reo Māori is recognised Student B: Yeah, I have a couple of teachers who will try and then ask to just check that they've got it right, to try and improve Researcher: How do you feel about that?

Student B: I think that that's good, that they're trying and wanting to learn

The majority of students wanted teachers to ask for help more, particularly if they didn't know the correct pronunciation of a Māori word. They suggested teachers ask peers and students. Many students felt that there was no excuse for a teacher not to know basic words and phrases, because they thought that the teachers would have had Māori language study in the past, and due to the resources available in schools.

\footnotetext{
"Well to be honest I don't think there's much of an excuse for not knowing even just basic Māori words like 'Morena' and 'Kia ora' and even 'Kei te pehea koe?' 'cause when you look around there's actually a lot of advertisement for it especially... and I think it's more that teachers should try more...not 'cause they have to...but 'cause it's nice to hear it...I'm not asking for whaikorero or anything...but you know..."
}

Many students saw the use of te reo by teachers as a good acknowledgement of their culture, and wanted to see it used wherever possible. Most students did not think it needed to be used all of the time, but in subjects where it was relevant. For example all students expected it to be used in social studies but not in science or other language classes. Several students suggested that teachers start by using basic Māori words or phrases in class, and could write the date in te reo on the board. The 
students thought that te reo should not be used too much, too quickly and that it was important that all students in the class understood what was being said.

Researcher: Is it important for teachers to use te reo in the classroom?

Student A: Yes, because as we were saying, you don't get the opportunities [to hear te reo] but if your teachers are using it, it gives you more opportunities and the more you listen to it pronounced correctly the more likely you are to pick it up

Student B: Yeah, it's good for them to use it sometimes

Researcher: So they don't have to use it every lesson?

Student B: Yeah, not every lesson, just some

Researcher: and in those lessons? Just a little bit?

Student B: Yeah, so people get an understanding of what the teachers just trying to say

Student C: Yeah 'cause if they do too much then some students won't understand, but if they just say little bits then say what they're meaning...

Student A: and also maybe if they start with little bits but build up so by the end of the year they're using quite a bit more

Several students were unable to study Māori at school because they had not taken it in year nine. These and other students felt that there should be more opportunities to learn te reo in schools. For example there could be a special mixed level class for beginners.

Student A: I think we could have another Māori class, because I was just looking...I had to choose my options for next year...but to get into Māori you had to have done year nine [te reo] or equivalent, or had a little bit of a background in Māori...but some people have none, so if you missed out in year nine you can't start in year ten 
Student B: Maybe we could have a Māori development class or something for people of all years that can enter without...use the basics [te reo]

A common complaint from students was that teachers do not make enough effort to interact with Māori students or participate in their cultural events. Students thought that teachers should show interest in their lives, be concerned and demonstrate an understanding of their worlds. They wanted to see more teachers attend kapa haka practices or concerts, or even just ask the students about the activities they take part in.

\footnotetext{
"Well this might seem really mean, but none of them [teachers] come to our kapa haka stuff, but you know, as soon as [the school production] comes on they're all there"
}

In classes students wanted to see teachers using more activities that they could relate to. They wanted Māori signs used around the school ground, translating common words like 'toilet', and more motivating posters in classrooms, such as Māori people achieving well in sports or other fields.

Many other suggestions were given for ways teachers could improve and these are listed in no particular order of importance:

- Teach Māori tikanga and values e.g. not littering and looking after the environment

- Do not just use the kapa haka group for 'show' but encourage management and teachers to have real and meaningful interaction with the group

- Involve students in school meetings and decision making processes 
- Listen to students when they correct teachers' pronunciation and show that they are trying to change

- Do not rely on Māori students in the class to read Māori words - teachers should try it themselves first

- Be inclusive - treat everyone equally

- Use correct spelling of students' names

- Employ more Māori teachers 


\section{Student Summary}

Participants came from year nine to year thirteen. Distribution of the year levels was fairly even, except for the smallest group of year thirteen. This was a fairly accurate reflection of nationwide school rolls for Māori. All of the students felt they had at least beginner level ability in speaking te reo. Ninety-seven percent of participants studied Māori at school. The main reasons for these students were identifying as Māori and because the students saw the language an integral part of their culture, and they wanted to improve their fluency. The other students did not study it because they chose subjects specific to career goals and a lack of subject choice/ availability after year nine.

Students were able to negotiate research questions and issues that they felt were relevant. These included issues surrounding language pronunciation, te reo use in the classroom and wider school, Māori language as a subject, respect of the language and culture by students and teachers.

Pronunciation and language use was found to be a major issue for most of the students. Across all of the year groups the majority of students expected teachers and New Zealanders in general to pronounce te reo correctly. Many students thought that significant numbers of their teachers mispronounced te reo, but fewer students expected their teachers to correctly pronounce te reo, than they did for $\mathrm{New}$ Zealanders in general. Students often had negative emotional reactions to the perceived attitudes of their teachers towards their language and culture. They did acknowledge those teachers who made an effort and showed an appreciation of correct and more frequent use of te reo. They thought there was a wide range of reasons why te reo may be mispronounced including a lack of education, knowledge, negative attitudes towards its use and lack of opportunities to learn. Media was seen 
as an important influence on language use. The majority of students thought it was important to use te reo in class, although it often depended on the subject as to how it was used. The main reasons for expecting it to be used in the classroom included its importance as an official and indigenous language of New Zealand. Students felt it was beneficial for all to hear te reo used more often and correctly, to help people learn. A third of the students did not think it important to use te reo in the classroom. This was mainly attributed to the different levels of ability found in schools, amongst students and teachers, and it was felt that expecting te reo use was unfair to those with low ability. Another main reason was that the decision to use it or not should be left up to the individual and not imposed on them. Also, Māori language was not considered relevant in some subjects such as English or science.

Other issues emerged as being important such as respect of Māori tikanga and a need for better relationships between students and teachers. They felt a sense of belonging in the Māori classroom which was enhanced by the actions and presence of the Māori teachers. Students felt that the relationship between staff and students could be improved with the display of genuine interest in their lives at school including kapa haka practice and performance, and recognition of Māori student achievement. Fair and equal treatment of all students in a class was clearly important, as was improving the school environment so it reflected Māori students' worlds, by using Māori language signs and artwork.

Students have clear ideas and advice on how teachers could improve their use of te reo and relationships with students. The main improvements were in using correct pronunciation of personal and place names, basic words and greetings. They also thought that te reo should be used where possible and relevant, as a good acknowledgement of a student's culture. 


\section{Teacher surveys}

\section{Overview}

Five teachers participated in interviews and filled out a survey containing 13 questions. This survey provided some background information on the participants as well as asking some questions covered in the interview. The surveys showed that teachers came from a range of backgrounds, including ethnicities and teaching experience. All of the teachers had been given little or no te reo training as part of their teaching qualification. Most wanted to continue with some te reo learning in the future. All of the teachers thought that te reo had a place in their classroom and that the way it was pronounced would affect their Māori students in some way. Many different issues surrounding te reo use were raised. These included lack of confidence in using te reo, and few opportunities to hear it used correctly.

\section{Survey results}

The teachers came from a variety of backgrounds. One teacher was a British national of Hindu culture, and the rest were New Zealand born. Of these, one identified as being Chinese, one Māori and two Pākehā. English was their native language although all participants had studied other languages to different levels of ability. Two of the participants had been teaching between zero-four years, two between five-nine years and one had over twenty years experience. The ages ranged between twenty-five and sixty-five years. The teachers specialised in subjects including ESOL (English as a Second Language), Physical Education, Computing, and Social Studies. The teachers had trained at institutions around the country. These included Whitireia Community Polytechnic, Auckland College of Education, Ardmore College and Wellington College of Education. 
The teachers were asked about the amount of Māori language learning that had been provided during their teacher training. Three responded that there had been none at all. Two thought that there had been minimal or basic language learning. Three had carried out further study in te reo since then and two had not. The types of language learning included personal study, professional development courses offered by the school and school funded study towards a formal qualification. All five participants spoke some Māori language. Three considered themselves to be at beginner level and two at intermediate.

Four of the five teachers were interested in doing further Māori language learning. Some of the reasons for wanting to continue learning te reo were for the students.

\footnotetext{
"Yes absolutely! For me to go into a classroom and use reo...to see the kids faces!"
}

"Yes, because it shows a respect for the students and their culture"

Other teachers felt that it was important to them personally, for their own growth and satisfaction, and also as one of New Zealand's official languages.

\footnotetext{
“[Yes] Because I love it. Māori reo has become very important to my own learning/ wairua. It has become absolutely necessary to me doing and achieving what I choose to do and achieve in my career and personal life”
}

"It encourages more people to use it and it should be recognised as an official language. Also, I want to learn to use it better" 
The reason for not wanting to do further study in te reo was due to it being considered unnecessary for the teacher's subject area and was not a priority to the teacher at the time.

“[No] I don't teach any Māori students so [I] feel it is not needed at present. [I] have other more pressing areas to develop in"

All of the participants thought that it was important to pronounce Māori language correctly and that their pronunciation of te reo affected their Māori students. One reason for using correct pronunciation was to show respect for the language and to encourage the correct use by others.

"To honour the reo and to normalise the proper use of Māori in New Zealand society”

Another was to show respect for the students and to encourage good classroom relationships.

\footnotetext{
“Absolutely, especially students' names, because they are very personal. Also it does a lot of damage to teacher/ student relationships if you make mistakes, with pronunciation, and embarrass the kids"
}

Some teachers thought that it would be an important issue for some students, whether or not te reo was pronounced correctly. They also thought it showed respect for the students and lack of cultural understanding if the language was mispronounced. One teacher suggested it was about encouraging the students' to identify as Māori and showing them that the language and therefore their culture is valued.

\footnotetext{
"[Correct pronunciation] Helps them to feel valued and respected which in turn helps their self esteem and their want/ choice to identify as Māori"
} 
One suggestion was that how much students were affected depended on the historical relationship between their own ethnicity and that of the teacher. For example, students may have more negative feelings towards a Pākehā who mispronounces te reo, while not being so affected by a Māori teacher who mispronounces te reo.

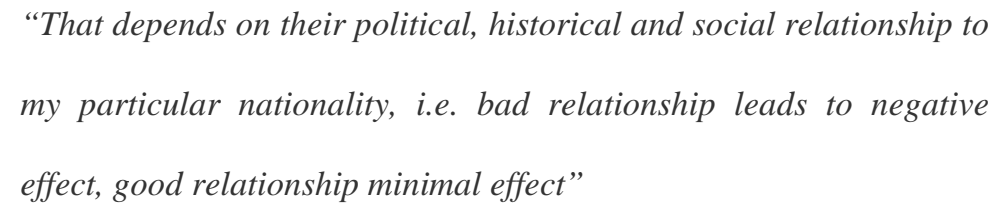

Another comment was that students may have low expectations of teachers and language use in general, because they hear it mispronounced so often.

"I think it does [affect them] most of the time, but the students won't always let you know that they mind. They might not even realise it themselves because they are so used to hearing it [mispronounced]"

Finally, teachers were asked to write down some of the issues for them when using te reo in the classroom. This was covered in greater depth during the interviews. The main issues recorded were (in no particular order):

- Time required for learning

- Access to quality professional development within schools

- Limited opportunities to use and listen to te reo

- Deciding how much or how little to use in classrooms

- Lack of resources and support for Māori language

- Personal ability in using te reo and confidence 
- The need to get through a subject curriculum does not allow time to incorporate a lot of te reo and most curricula do not include Māori language

- Te reo is not relevant in their particular subject so it is difficult to use it in the classroom. 


\section{Teacher interviews}

\section{Overview}

The interviews were based around four main questions; What place does Māori language have in the classroom? What is difficult/ easy about using Māori language? In what ways do Māori students react to Māori language use in the classroom? Are there any other issues that affect your speaking of te reo in the classroom?

Most of the teachers agreed that te reo had an important place in the classroom and that schools had a responsibility to teach and encourage correct use. The level of use was thought to be related to the subject and/ or classroom population. Teachers found it difficult to learn new words or build on their current knowledge because of a lack of opportunities to hear it spoken and difficulty accessing quality professional development. Their level of te reo skill also influenced their confidence in using it in their lessons. Teachers found it difficult to gauge the reactions of their Māori students. However, they felt that there were less negative responses or behaviours from Māori students when an effort to incorporate Māori culture into the classroom was made. Many other issues were raised including the difficulty in using te reo in some subject areas and curriculum, importance of support from school management and other staff and the need to get background information on students early in the school year.

\section{Māori language in the classroom}

Several teachers believed that Māori language should be compulsory in secondary schools. They also felt that it was an important part of a student's education to learn about the indigenous culture of New Zealand. It was therefore the 
school's responsibility to provide that education and ensure all students gained some knowledge of the history and language of Māori.

"I think if they start teaching it [te reo] at a young age they'll have all these kids that are non-Mâori, they'll be able to pronounce the words, they'll be able to get out there and say 'Hey you know, I understand... why you don't put your bum here, I understand why you don't put your chopsticks up like this'...it's almost like anything in life when you're taught from a young age you learn to accept it...if 30 years down the line you're being taught something it's like all your habits and all the things are ingrained in you so if someone's trying to introduce something new you might be quite resistant to it. So I think, yes, get it into the schools, start early, and it's a fabulous thing, it's a great opportunity to learn something completely different, to learn the language, to be around people that are different from you, it's such a privilege”

(Teacher $K$ )

Several teachers thought that the use of Māori language was determined by the school environment and classrooms. In one teacher's school Māori made up 40 percent of the student population and Pacific Islanders made up another 40 percent. They felt that in multicultural schools it could be difficult to focus solely on Māori language or culture. Also, in some subjects te reo was considered to be either irrelevant or difficult to incorporate due to the type of vocabulary specific to that subject.

“Well [te reo] it's got a special place, but such a high percentage of our students have English as a second language in the entire school that if you...they're struggling enough with English so if you 
suddenly start to make a remark in Māori they have got absolutely no idea, so you could get the majority of your class being confused."

(Teacher E)

"There are situations, if you are in a predominantly...class of students from that Māori background, that can be used. It does depend on the particular classroom situation.”

(Teacher $M)$

Most of the teachers agreed that te reo had a special place in education in New Zealand, both inside and out of the classroom. They thought it important to teach common words such as greetings and places names, so that students would be able to communicate effectively.

"If it's a word, a Māori word that is widely used in New Zealand, that we know they're going to need to know that word because it's in common usage, for example 'whanau', place names that are commonly used, particularly the ones that are used in the area they are living, then there's definitely a place...well we have to use them because...our language is becoming increasingly mixed with the two."

(Teacher E)

“I think it holds quite an important place. I think it's important for the Māori kids but at the same time I think it's quite important for the other children too because it's not just about having Māori in the classroom for the Māori kids and then not worrying about the Pākehā kids because it's about educating everyone."

(Teacher $K$ ) 
"In a normal New Zealand class which has a number of Māori and other ethnic groups, I would say 'Kia ora', 'Good morning' and 'Hello' in Chinese just as an icebreaker. But I recognise that New Zealand is a multicultural country of students, teachers, from different ethnic backgrounds...it's just a courtesy to acknowledge that."

(Teacher $M)$

One teacher thought that to help the language we need to normalise correct pronunciation and language use in schools. This also gives non-Māori a chance to hear it spoken and learn about the language and culture.

"Expression is a wonderful thing and that is the expression of things in Māori, in waiata and being able to do things in Māori, which are wonderful things to be able to do and be able to participate in and a lot of Pākehā haven't had that opportunity 'cause it's been taken from our education systems...So not only have Māori been ripped off but Pākehā have been ripped off too and everyone else. So why should Māori be done in schools? So that everyone can participate in Māori things and so that everyone can feel confident and not ashamed.” (Teacher J)

"It's almost like these little boxes these teachers have and they put their colours in there and their numbers and they put their greetings in and they do these 3 boxes and that's it 'Yeah we teach Māori' but it's not about that. There is a lot more things that go with it like tikanga and making sure the kids are not putting their bums on the table."

(Teacher $K$ ) 


\section{Factors influencing Māori language use}

There were a few common difficulties faced by teachers when using or

learning te reo. They felt they lacked some confidence in using it in the classroom because of their limited knowledge and vocabulary. They also complained about lack of opportunities to hear and learn new words and correct pronunciation.

"I think it's ensuring that you get the correct pronunciation and obviously it's a confidence based skill issue in that. You wouldn't want to try something that you weren't sure how the phrase was pronounced or else you look like a blimmen fool."

(Teacher $M)$

Researcher: So what is difficult or easy for you about using the Māori language?

Teacher E: What's difficult is I have such limited vocabulary in Māori. Another difficulty is I don't hear it spoken enough to be able to pick it up or hear the correct pronunciations

Researcher: Do you mean in schools or in your general life?

Teacher E: Both, particularly in schools...but if I'm listening to the media...one hears it so infrequently in the environment I'm in

"I've only heard it spoken fluently a number of times, in a school situation, by teachers of Māori. I was doing some work in the staffroom and they were having a conversation in Māori...I had never heard that before in New Zealand...in Wellington, I've only really lived in Wellington, I've not heard a conversation in Māori. In this metropolitan, urban environment, it's not really commonly spoken.” 
(Teacher $M$ )

The teacher from overseas was particularly surprised at the lack of Māori language being used in everyday situations.

“We were in Woolies...your supermarket...and we were walking
down the aisle and I stopped and looked at my partner and said 'God
there's no Māori [language] here' and you don't hear it. It's so
weird, if you were in Japan you'd hear people speak Japanese, if
you're in India you hear people speak Hindi. You're in New Zealand
and you don't hear Māori, there's no one speaking here, everyone's
speaking English...I think that's so strange."
(Teacher K)

Several teachers found it difficult to incorporate Māori language into subjects, because of the pressure to get through set curriculums and maintain classroom control.

“As a teacher you don't want to look silly in front of the kids, that puts you on the back foot when you're struggling to get through the class sometimes...your goal is to maintain classroom control and complete your lesson topics so the focus is on doing teaching."

(Teacher M)

It was also suggested that the New Zealand curriculum makes it difficult to teach Māori students appropriately, using te reo in the classroom, or other relevant styles of teaching.

“I reckon what does work for Māori students doesn't really fit into this whole education system... 'Kotahitanga' styles is about studentcentred approach, it's about building and sustaining good relationships and basically we can do those things but it's hard to do 
when you've got 30 kids in the classroom. It's hard to do when

you've got a curriculum you've got to [teach]... of course we aim to do those things but sometimes to do those things you've got to relax on other things...less focussed on some bullshit curriculum, more focussed on 'what's up man, how you feeling? What are your needs out of this?' and those two ideas don't always gel together that well."

(Teacher J)

Issues for teachers included getting students to respond to and use te reo. In one case a parent visited the school and complained that his son was being asked to greet the teacher as 'Matua'. The teacher had support from their school management at that time, but had experienced less support from other schools when in the same situation. They had been actively discouraged from introducing themselves as 'Matua ___. Other teachers also found it hard to get their students to reply to greetings in te reo. Difficulties arose when teachers assumed that students would understand basic words, and realised that they needed to translate most of what was said. They found it hard to determine the reasons why students did not use Māori, and felt it would be helpful to receive information about their classes at the start of each year, particularly to find out their cultural backgrounds. One teacher felt it was easier to learn and use te reo when fluent in other languages, and that working with Māori students was a great motivator to learn and use it more themselves.

\section{Reactions from Māori students}

There were no reports of obvious or overt reactions to teachers' use of te reo in the classroom. However, several teachers felt that participation in activities and the absence of any negative responses was a good indication that students reacted 
positively to te reo being used. Students' greeting teachers in te reo was also a positive result of the teachers using similar greetings at the start of lessons. In one instance a teacher gave instructions in te reo to her class. She found that a few of the Māori students voluntarily translated for the rest of the students, and seemed to show pride in their ability to do that.

While none of the participants had experienced negative verbal responses to te reo use in the classroom, they had heard of it occurring in other classrooms. The students had reacted to another teacher using Māori waiata during the lesson, by making negative comments. One teacher attributed this to the students rebelling and pushing boundaries in behaviour, rather than having any kind of negative attitude towards Māori language.

\section{Issues for teachers}

There was a wide variety of issues reported by teachers. Some issues have been covered in the previous questions. No clear issue stood out as being more or less important than others, although several teachers had mentioned previously that they would like to hear te reo spoken more often in order to learn better pronunciation. The issues here are presented in no particular order of importance.

The level of support from senior management in schools was a factor in allowing and supporting a teacher to use and learn te reo. They were encouraged to try different strategies with Māori students and given funding and time off to study towards a formal qualification in Māori studies. An inclusive policy within the school also enabled teachers to feel comfortable trying new things in lessons, just as students were encouraged to be individuals and respect the rights of others. There was a feeling amongst a few of the teachers that it was difficult to incorporate te reo in classes that had a large proportion of non-Māori students. 
"I don't use a whole lot of Māori a whole lot, just a little bit. But I know that, for example, $X$ [teacher]...has tried more in some of his classes with all Pākehā kids and had little success."

(Teacher $J)$

One teacher felt it was important to help the rest of the school staff feel comfortable with some things Māori, and helped teach waiata during staff meetings. When it came to studying te reo, a factor for one teacher was their upbringing as Māori, and some experiences with racism. The teacher had learnt te reo later in life, and their motivation to learn developed in relation to their improved sense of selfesteem and identifying as Māori. As this teacher gained more confidence in using te reo, they used it more often and in turn learned more of the language. Sometimes the teacher was forced to use te reo because they were the only Māori teacher present and was therefore expected to officially open a hui or meeting.

It was considered important by one teacher, that all New Zealand children have some level of te reo ability. Teachers and senior management would all need to support this and actively encourage the learning and use of te reo, in order for it to happen.

It was recognised by several teachers that they need to be sensitive to the backgrounds and cultures of the students in their class. Sometimes it was assumed that all students could understand common Māori vocabulary, but this was not the case. It was also suggested that teachers should not expect that Māori students understand the language, because it could lead to embarrassment for the student if they did not. One way of avoiding this would be to get detailed and relevant information about the students in their classes, at the start of every year. This information is not always readily available, and can take a long time to find out. In a 
class with no Māori students or with large numbers of second language speakers, it was important to take care in the level or amount of te reo used. If too many Māori words were used, students could become confused and not understand the lesson.

In some classes it was found to be difficult to interest students in learning te reo because they were so focussed on academic success. They did not see value in learning the language. The teacher also acknowledged that they did not actively teach the students to see value in speaking te reo. In one school there was a large problem with racism and fighting between Māori and other cultures. A teacher felt that this made it difficult to show too much support for Māori language in classes with large numbers of non-Māori students.

One teacher thought that they would avoid using te reo altogether, rather than risk making a mistake with pronunciation. Another teacher wanted to see more professional development in Māori language offered at schools and was frustrated with other staff not pronouncing te reo correctly. 


\section{Teacher Summary}

The five teachers who participated in the study came from a variety of backgrounds including Hindu, Chinese, Māori and Pākehā cultures. They had a range of teaching experiences from newly graduated to over two decades. The teachers specialised in several different subject areas such as physical education, computing, English language (ESOL) and social studies. They had gained teaching qualifications at providers around the country including Whitireia Community Polytech, Auckland and Wellington Colleges of Education, and Ardmore College.

All of the teachers had experienced little or no formal Māori language learning during their teacher training, and most wanted to do further study to improve their Māori language skills. Reasons for this included personal satisfaction and to show respect for Māori culture. Where further study was not a priority, it was due to the language being considered unnecessary to the teacher's subject area. Some had carried out further study of te reo through personal study or professional development provided by schools. All of the participants stated they had at least beginner level ability in speaking te reo.

All of the teachers thought that correct te reo pronunciation was important and that it affected their Māori students in some way. A major reason for using correct pronunciation was to show respect for the culture of their students, to help foster positive attitudes towards identifying as Māori and to be good role models for correct use of the language. One opinion was that the way students were affected was determined in part by their relationship with the teacher, in particular their culture's historical relationship with the culture of the teacher.

It was also agreed that te reo has a place in the classroom, with most teachers agreeing that schools had a responsibility to teach and model correct language use. 
However, several teachers felt that the level of use depended on the students' backgrounds and the subject. It was also considered important to incorporate Māori tikanga and mātauranga in classroom teaching.

It was perceived by teachers that their use of Māori language did affect their students, but often they were not sure exactly how. Teachers thought that a reduction in negative behaviours in the classroom was a good indicator of positive reactions to Māori language use, as was increased participation in classroom activities by Māori students.

Many different issues arose surrounding te reo use, some were common among several teachers, but most were specific to the individual. The most common ones were lack of confidence in their ability and knowledge of te reo, and few opportunities to hear correct te reo spoken and therefore to improve their vocabulary and ability. Other issues were; fitting te reo into subject curriculums because of time restraints, getting time and support from school to use and learn te reo, the level of support for Māori language and students in general from school staff and senior management, families and communities, and needing relevant knowledge of student backgrounds in order to provide relevant teaching and learning opportunities. 


\section{Chapter six: Discussion of findings}

This section interprets the information found by the current study. It includes a discussion on how well the information answers the initial research questions. It also identifies the limitations and strengths of this study and makes some recommendations for future research. The implications of these findings are examined and then finally, the overall conclusions of this study are presented. The research questions were:

1. How does the way Māori language is, or is not, used in the classroom (including factors such as tone, style or pronunciation) impact the learning of Māori students?

2. Can the holistic schooling experience become more positive for Māori by enhancing the use of te reo by teachers and students?

3. In this context, what does 'enhance' mean for Māori students?

4. What are the issues for teachers when they do, or do not, use Māori language in the classroom, including any needs for further professional development and support?

As far as can be established by this qualitative research, the way te reo Māori is used by teachers and students in secondary schools does have an impact on Māori students. In this study students were aware of and affected by language use, particularly its pronunciation. They also related the way te reo is used by a teacher, to that teacher's attitude towards and respect of the Māori culture. Such respect is in turn related to the perceived respect for the student. However, it is difficult to gauge from the results how much influence factors such as tone and style of language had on the students. The participants did not voluntarily raise these as relevant factors 
and so this may suggest that pronunciation of language was the main linguistic feature to have any influence on students.

Most of the students interviewed could give examples of teachers who mispronounced te reo at some time during their lessons and the students verbalised their negative reactions to hearing it. This was also found in Bishop and Berryman's (2006) study, where students stated that mispronunciation of te reo made the schooling experience less positive for them. Students also stated other things could improve their schooling experience. They include making the school environment more reflective of Māori culture and teachers building relationships with students by showing interest in and knowledge of their culture. These other issues arose just as often in the data and had as much importance to students as te reo use. The study results suggest that there is significant potential to enhance the relationship between teacher and student by improving the way Māori language and culture is utilised and reflected in the school environment.

One particular theme that emerged was the desire of students to see teachers making an effort to incorporate Māori language and culture into the lesson and the physical classroom space. The act of showing interest in the students' worlds and their culture and language, had a significant impact on the students. This suggests that the students will make judgements on a teacher's attitude towards them and their culture, based on many things. For example, if a teacher mispronounces a Māori word, but asks for help in getting it right, or shows some interest in learning how to pronounce te reo correctly, then the act of mispronunciation had little or no affect on the student. The major issue for the students was on the attempt rather than the outcome. 
The expectations of Māori students indicate that they are eager for positive change. The students had high expectations of their schools and teachers and had clear ideas on how the school experience could be enhanced. They saw teachers as being an important part of this process, as the majority of suggestions related to teachers and their language use. This supports the literature that theorises teachers as having the most influence on student learning and achievement (Alton-Lee 2003). The majority of the students interviewed felt that New Zealanders in general should be expected to pronounce te reo correctly. When teachers in particular use te reo, the students verbalised mainly negative associations with mispronunciation, such as laziness, lack of care for the language and even racism. If the language attitude theorists such as Cooper and Fishman (1974), Deverson and Gordon (1989) are correct, then the students are likely to associate the poor use of te reo with a teacher's attitude towards the culture. This was suggested by Holmes (1982) as a cause of misbehaviour or negative reactions to the teacher. This theory was supported here, as some teachers reported less negative behaviour when te reo was incorporated into lessons. Students may also make judgements of the attitudes of their teachers, based on verbal and non-verbal cues such as negative verbal responses by teachers to a student being absent to attend a tangi, or lack of attendance by teachers at kapa haka practices or performances.

Approximately 70 percent of the students thought that at least one of their teachers mispronounced te reo. Of these students nearly half had heard mispronunciation from four or more of their teachers (out of an average of five or six teachers). This is a substantial proportion of teachers who, according to the expectations of their students, are not using te reo correctly. This indicates a need for further professional development in schools for teachers to improve such things as 
their awareness of correct pronunciation. Some teachers did not clearly identify language use as being a tool in developing relationships with their Māori students, whereas other teachers strongly felt it was a good acknowledgement of a student's culture and therefore a good building block for positive classroom relationships. All of the teachers also reported a lack of language learning during their teaching qualification and few opportunities to hear te reo used correctly. These issues raise questions regarding pre and post-service training for teachers, and the roles of teacher training providers. This gives some support to the provision of professional development programmes such as Te RITO, aimed at improving Māori language use and teaching in Northland schools. It also suggests a need for these programmes to be provided in more areas and a greater number of schools.

Some teachers reported feeling uncomfortable or even unable to use te reo in classrooms that had a majority of non-Māori students. If such teachers only choose to use te reo with Māori students, then this may imply that the language is not valued by everyone and should only be used around Māori people. It may even perpetuate racism in the school. For example, where one teacher suggested that it was difficult to use te reo in classes because of the hostility between Māori and other cultures in the school, the decision not to use Māori may further reduce the value that it, and the culture, has in that school.

At times some participants appear to reflect the attitudes of New Zealand society in general, as suggested by Bishop and Glynn (1999). They discuss the reasons why people tend to take language study, such as for functional reasons or for perceived economic benefits. Several teachers did not appear to value te reo personally. Although they did see it as a tool to help their teaching of Māori students, it seemed to be an 'extra' rather than the norm, something to be fitted into 
the lesson if there was time. Some teachers also displayed deficit thinking as discussed by Bishop et al (2005). The teachers in part blamed factors such as stringent curriculum and teaching outcomes, politics, colonisation, school management, student population, parents or community attitudes for the way they were able to use, or not use, te reo in schools. For example one teacher saw the historical relationship between Māori and Pākehā impacting on how the students would react to the teacher's language use. The teacher appeared to believe that because the Māori had had a negative experience during and since the English colonisation, the relationship between Pākehā and Māori was compromised. The result of this being that any perceived errors in pronunciation may not be forgiven as easily when committed by a Pākehā. The teacher seemed to think that perhaps Māori students would be more likely to forgive or ignore language errors if spoken by a person not of English descent. They are suggesting that how students react to a teacher is not related solely to their language use, but to historical conflict occurring through colonisation. In some ways this may be true, but the teacher does not appear to be taking responsibility for the potential impact their language use has on their students.

Much of the literature suggests that using the language of minority students positively in the classroom will have benefits for the classroom relationships (Holmes 1982). Using Māori language in an effective and meaningful way should then help teachers connect with their Māori students. If the research by Bishop et. al. (2003) and others is correct, an improved teacher/ student relationship will eventually lead to improved outcomes for student achievement. This suggests that the use of Māori language and tikanga in secondary schools could be an effective tool in reducing the gap for Māori in educational achievement. 
Qualitative research can provide the opportunity to develop an expressive, deeper understanding and insight into individuals' beliefs, concerns, attitudes, motivations, aspirations, culture, behaviours, and ideals. It allows us to discuss a topic or idea with target audiences and get a better insight into what and how people think and feel about a topic or idea. It helps us to understand the language individual's use and to find out the motivations that underlie certain behaviours.

A major limitation of this qualitative study is that these results cannot be statistically applied across the target population (Māori secondary school students and teachers). This is due to the methods involved in this study, such as interviews and focus groups, which by design are different from those methods that may be used in a quantitative study that may be applied to broader populations. In particular the participants were not selected randomly. Qualitative research does not collect numeric data from a representative sample of the target audience. Therefore this study cannot undergo statistical analysis to estimate to what extent opinions expressed by participants reflect the opinions of the population studied. The most important implication of this is that it is inappropriate to draw any conclusions about the actual popularity of specific concerns, attitudes, or beliefs among the target audience.

However, an advantage of carrying out this qualitative study is that it may help to plan some effective quantitative studies in the future and may also be useful in interpreting or exploring the selected topics further.

Time was a major restriction in the implementation of this study. Further research needs to be done incorporating more schools and a greater sample size. It was very difficult to recruit teachers to be interviewed. It was intended that the teacher interviews would be repeated, but this was not able to be done in practice. 
Teachers are generally very busy during school hours and so interviews were carried out mainly after work hours. Understandably teachers are not as enthusiastic about participating in their own time. The relationship that is developed with the teachers prior to the interviews is very important and would be absolutely critical in carrying out repeated, in-depth interviews.

It may be useful to analyse school and government policy documents to find out if any formal guidelines exist for the use of Māori language in schools. If they do, then it may be an avenue of research to examine how effectively they have been written and utilised by policy makers and schools. Documents such as these can be important tools for boards of trustees and school management to guide the teachers in their practice and learning. The teachers in this study did not have any awareness of such documents either at a department or school level. The lack of clear policy regarding language use in schools may be reflective of a past and/ or present government strategy which until now has failed to acknowledge the importance of te reo in schools.

Access to schools was a difficult hurdle to overcome, early on in the research process. This was not anticipated. In a major city with a large university, the schools were often asked to participate in research. The school principals were initially difficult to contact, and when contact was made, were not overly keen to participate. One of the reasons for this was the high number of requests they get each year from university students carrying out research. The schools seemed to be wary of putting their staff under further stress or increasing their workloads. They also warned that surveys may not be very effective for teachers as there was usually a low return rate of completed surveys - whether they were from university students, the school itself or other agencies. The process for initial contact and relationship 
building with the school staff and management was also one of the most important steps. Without this it is difficult, if not impossible, to gain access to a large sample size of students.

One of the strengths of this study was the repeated focus groups carried out with students. The students reacted positively to meeting the researcher a second time and appeared to be more confident and relaxed during the discussions. It was effective in allowing greater in-depth talk around issues that had been previously raised, and students were able to go into much more detail during the second focus group. They also demonstrated clear and strong opinions regarding other issues besides language use and raised new ideas and discussion topics in the second meeting. A disadvantage of focus groups is that some participants may tend to express views that are consistent with social norms and try not to present themselves in a negative way. This bias towards social desirability may influence respondents to censor their own opinions, especially when they are in a group setting.

A broader selection of teachers would be recommended in further studies. Factors such as gender, teaching experience and ethnicity, may have been an influence on their teaching practice. It would be beneficial for a sample to include a wider selection of potentially influential factors, and be as random as possible, as opposed to the sample of convenience that was used in this research. Another factor may have been that only teachers confident in using Māori language, or with positive attitudes towards the culture, language and students, may have volunteered for this study. A wider range of schools would provide a greater insight into the varying school environments and teaching practices. Schools in rural areas or with larger populations of Māori students and teachers may provide different results. Future research could aim to get a randomly selected sample of teachers, from a wider range 
of schools and locations. It would be interesting to examine any differences in schools from North and South Islands, as well as regions within each, such as Northland or the East Coast, with the higher populations of Māori.

No testing or observations were made of the current level of te reo used in the targeted schools. It may be useful to undertake a quantitative study to make some type of measurement of things in schools such as the level of te reo used in classes, the use of signage in te reo and other physical reflections of the Māori culture. Research might also attempt to identify the factors involved in schools where students report positively on the level and standard of Māori language use. This would be particularly helpful in recommendations for other schools in their policy and the future training of new teachers by providing indicators of success and models of good school structure and management.

This research suggests that while teaching and teachers remain the clear influence on success for Māori students, Māori language could be a useful tool in building successful relationships with students. This needs to be reflected in official policy and documented clearly for the guidance of schools and educators. It could be accompanied with clear and practical methods to incorporate the language into school policy, environment and classroom practice. The results also suggest that there is still much work to be done towards the development of positive attitudes towards the Māori language, among Māori and non-Māori and to encourage all New Zealanders to value it personally. Schools are a good environment to begin this change. As demonstrated in the project Te RITO, when students learned te reo at school, their parents became involved by learning it themselves or having more interaction with the school itself. Until now Te RITO has been implemented only in areas with large populations of Māori. It could be useful to introduce Te RITO to 
schools where Māori are a minority, such as those in this study and to measure in some way the impact Te RITO has, not only on Māori language use, but on overall academic achievement.

This research identifies some issues for teachers when learning and using te reo in the classroom, such as a lack of confidence and opportunities to learn, use and be involved with Māori language and culture. This may provide an additional focus for enhancing professional development programmes and teacher training establishments. There is a need for more support in terms of language learning and resources. Teachers should be encouraged to gain confidence with te reo, and in relating to different cultures. Such improved focus on te reo in initial and ongoing teacher training would provide a wide range of benefits for teachers, students, schools and the wider community. In particular, improved te reo skills could help bridge gaps for Māori students. It would help remove some of the institutional obstacles they face in gaining better academic performance.

All of the teachers reported a lack of language learning during their teaching qualification and few opportunities to hear te reo used correctly. These issues raise questions regarding pre and post-service training for teachers, and the roles of teacher training providers. Again Te RITO would be a useful professional development programme for all teachers and schools to address these problems. While the sample of teachers in this study is small, the overwhelming response was that teacher training establishments are not providing Māori language learning to a suitable standard. There needs to be some sort of formal assessment of the current standard of teacher training, in terms of Māori language and culture. This could involve a quantitative study of courses offered at teacher training establishments, including a measure of the proportion of time given to te reo and tikanga study. 
The Ministry of Education may need to revise their national policy guidelines for teacher training establishments, to make clear the roles of both the government and institutions in upholding the expectations of the Treaty of Waitangi. At the moment the statistics clearly demonstrate a failure by some part of the educational process - whether wider policy, teacher training or schools - to engage Māori students. Since the literature has identified teachers and their teaching practice as being the biggest factor influencing student achievement, then the teaching of teachers should be a major concern of educational policy. While individual teacher training establishments have autonomy to some degree, the government has the responsibility to ensure Treaty of Waitangi expectations are being met. To do this they may need to put a greater focus on how teachers are being taught and how they are being trained to work in increasingly multicultural classrooms. 


\section{Conclusions}

When features of te ao Māori, including te reo and tikanga, are reflected positively in the school practices, values and environment, the overall learning experience may be enhanced and become more positive for Māori students. For the sample of students in this study 'enhanced' meant changes for teachers and their teaching practice, which supports the literature that suggests teachers are the greatest factor in learning and achievement. These students see teachers as playing an important role in modelling positive attitudes and behaviours particularly with correct language use. The level of impact this has on Māori students deserves further research, as does the development of strategies to address the issues surrounding Māori language use. Research such as this has the potential to help reduce the gap between Māori and non-Māori educational achievement.

In the past, the training and professional development provided for the teachers in this study, was not at a standard which currently enables them to incorporate Māori language and culture in their classrooms in a meaningful or effective way. However, the small sample size of teachers in this study makes it difficult to state any clear conclusion. Instead it is suggested that the quality of Māori language and tikanga courses during teacher training needs to be researched and evaluated in greater depth. A recommendation is also made that in the future, professional development programmes and educational policy aimed at the teaching practice within secondary schools should include aspects of Māori language and tikanga learning. 


\section{References}

Alton-Lee, A., 2003. Quality Teaching for Diverse Students in Schooling: Best Evidence Synthesis. Wellington: Ministry of Education.

Benton, R. A., 1987. From the Treaty of Waitangi to the Waitangi Tribunal. In W.

Hirsh (ed.), Living languages. Bilingualism and community languages in New Zealand. Auckland: Heinemann, pp. 63-74.

Berryman, M., \& Bishop, R., 2006. Culture Speaks. Wellington: Huia Publishers

Bishop, R., 1996. Collaborative Research Stories. Whakawhanaungatanga.

Palmerston North: The Dunmore Press Ltd

2005. Changing Power Relations in Education: Kaupapa Māori Messages

for Mainstream Education in Aotearoa/ New Zealand. In F. Bodone (ed.),

What difference does research make and for whom? New York: Peter Lang.

and Berryman, Cavanagh, T., \& Teddy, L., 2007. Te Kotahitanga Phase 3

Whanaungatanga: Establishing a Culturally Responsive Pedagogy of

Relations in Mainstream Secondary School Classrooms. Ministry of Education.

Bishop, R., Berryman, M., Tiakiwai, S., \& Richardson, C., 2003. Te Kotahitanga: The experiences of year 9 and 10 Māori students in mainstream classrooms. Ministry of Education.

Bishop, R., \& Glynn, T., 1999. Culture Counts - Changing Power Relations in Education. Palmerston North: Dunmore Press Ltd

Bradley, S., Draca, M., Green, C., \& Leeves, G., 2006. The magnitude of educational disadvantage of indigenous minority groups in Australia Journal of Population Economics, 20(3): 547-569.

Burgess, R. G., 1984. In the field. An introduction to field research. London: Routledge

Cameron, M., Mitchell, L., \& Wylie, C., 2002. Research focuses on student achievement and learning. New Zealand Education Review, 7(43).

Cooper, R., \& Fishman, J. A., 1974. The Study of Language Attitudes. International Journal of the Sociology of Language, 3: 5-19.

Cresswell, J. W., 2005. Educational Research. New Jersey: Pearson Education. 2 edn.

Deverson, T., \& Gordon, E., 1985. New Zealand English. An introduction to New Zealand speech and usage. Auckland: Heinemann 
and E. Gordon, 1989. Finding a New Zealand voice. Auckland: New House Publishers

Else, A., 1997. Māori Participation and Performance in Education. A summary report. Ministry of Education.

Flude, M., 1974. Sociological Accounts of Differential Ability. In M. Flude \& J. Ahier (eds.), Educability, schools and ideology. London: Croom Helm.

Grant, C. A., \& Sleeter, C., 2007. Making choices for multicultural education. Five approaches to race, class and gender. U.S.: John Wiley

Hattie, J., 2003. New Zealand Education Snapshot: With specific reference to the Years 1-13. Paper presented at the Knowledge Wave 2003: The leadership forum.

2003(b). Teachers make a difference: What is the research evidence? Paper presented at the Australian Council for Educational Research Annual Conference on 'Building Teacher Quality', October.

Holmes, J., 1982. Language for learning. Wellington: Department of Education

1987. Providing Support for the Language Learner. In W. Hirsh (ed.), Living languages. Bilingualism and community languages in New Zealand. Auckland: Heinemann, pp. 7-16.

Kaa, W. M., 1987. Policy and Planning: Strategies of the Department of Education in Providing for Māori Language Revival. In W. Hirsh (ed.), Living languages. Bilingualism and community languages in New Zealand. Auckland: Heinemann, pp. 55-62.

Lingard, B., 2002. Research focuses on student achievement. New Zealand Education Review, 7(43).

Lovegrove, M., 1966. The scholastic achievement of European and Māori children. New Zealand Journal of Educational Studies, 1(1): 16-39.

Ministry of Education, 1997. Adult Literacy in New Zealand: Results from the International Adult Literacy Survey. Wellington: Ministry of Education. 1999. Report of the Literacy Taskforce. Wellington.

2003. Schooling in New Zealand. Wellington: Ministry of Education.

2004a. Focus on Māori Achievement in Reading Literacy - Results from PISA 2000. Ministry of Education.

2004b. An overview of some key national Year 5 and Year 9 achievement results: Findings from the Trends in International Mathematics and Science Study (TIMSS) 2002-2003. Ministry of Education. 
2004c. Te Hiringa i te Mahara. A Pathway to Success - Summary handbook for New Zealand secondary schools. Ministry of Education.

2005. School Leavers data. Wellington: Ministry of Education.

2006. State of Education in New Zealand. Ministry of Education.

2007a. Achievement at Māori immersion and bilingual schools. Update for 2005 results. Wellington: Ministry of Education.

2007b. Education Report - Students Going to School in 2007. Wellington: Ministry of Education.

2007c. Ka Hikitia - Managing for Success. The Draft Māori Education Strategy 2008-2012. Wellington: Ministry of Education.

2007d. Te Reo Màori in the New Zealand Curriculum. Learning Media.

Ministry of Statistics, 2001. Census of New Zealand. Ministry of Statistics.

2006. Census of New Zealand. Ministry of Statistics.

2007. Quickstats About Māori - Census 2006. Wellington.

Nash, R., 1993. Succeeding generations. Family resources and access to education in New Zealand. Auckland: Oxford University Press

and J. Prochnow, 2004. Is it Really the Teachers? An Analysis of the Discourse of Teacher Effects on New Zealand Educational Policy. New Zealand Journal of Educational Studies, 39(2): 175-192.

Nechyba, T., McEwan, P., \& Older-Aquila, D., 1999. The Impact of Family and Community Resources on Student Outcomes: An Assessment of the International Literature with Implications for New Zealand. Ministry of Education.

and McEwan, P., \& Older-Aquilar, D., 2007. The Impact of Family and Community Resources on Student Outcomes: An Assessment of the International Literature with Implications for New Zealand. Wellington: Ministry of Education.

Post Primary Teachers Association Collective Agreement, (2004).

Oakley, A., 1981. Interviewing women: a contradiction in terms. In H. Roberts (ed.), Doing Feminist Research. London: Routledge and Kegan Paul, pp. 30-61.

Openshaw, R., 2007. Evaluation of Te Kotahitanga - Phase 3. Massey University. 
Pallas, A., Natriello, G., \& McDill, E. L., 1989. The changing nature of the disadvantaged population: Current dimensions and future trends. Educational Researcher, 18(5): 16-22.

Pihama, L., 1993. Tungia te Ururua, kia tupu whakaritorito. Te tupu o te harakeke: A critical analysis of parents as first teachers. University of Auckland.

Reinharz, S., 1992. Feminist methods in social research. New York: Oxford University Press

Siegel, J., 2007. Creoles and Minority Dialects in Education: An update. Languages and Education Journal, 21(1): 66.

Simon, J., 1990. The place of schooling in Māori-Pakeha relations. Unpublished Ph.D, University of Auckland.

Smith, G. H., 1990. Research Issues Related to Māori Education. Paper presented at the NZARE Special Interest conference, Massey University, n.d.

1997. The Development of Kaupapa Māori: Theory and Praxis. Unpublished Ph.D thesis, University of Auckland.

Smith Tuhiwai, L., 1999. Decolonizing Methodologies. Research and Indigenous Peoples. Dunedin: University of Otago Press

Sunwolf, \& Frey, L. R., 2001. Storytelling: The Power of Narrative Communication and Interpretation. In H. Giles \& P. Robinson (eds.), The New Handbook of Language and Social Psychology. Chichester: John Wiley \& Sons, pp. 119135.

Tajfel, H., 1981. Human Groups and Social Categories. Cambridge: University of Cambridge

Te Puni Kōkiri, 2001. Provisional Results of the 2001 Survey of the Health of the Māori Language. Wellington: Te Puni Kōkiri.

2002. Survey of Attitudes. Values and Beliefs about the Mãori Language. Wellington: Te Puni Kōkiri.

2004. Te Reo Māori i te Hapori. Māori Language in the Community. Wellington: Te Puni Kōkiri.

2007. The Māori Language Survey. Te Tirohanga ki te Reo Māori. Factsheet. Wellington: Te Puni Kōkiri.

and Te Taura Whiri i Te Reo Māori, 2003. Te rautaki reo Māori - The Māori language strategy. [Internet.] [Retrieved 9/4, 2007.] Available from: http://www.tpk.govt.nz/publications/docs/maori_\%20lang_strat_0903.pdf 
Tripp, D., 1983. Co-authorship and negotiation. The interview as act of creation. Interchange, 14(3): 32-45.

Tuuta, M., Bradnam, L., Hynds, A., Higgins, J., \& Broughton, R., 2004. Evaluation of the Te Kauhua Māori Mainstream Pilot Project. Wellington: Ministry of Education.

UNICEF, 2002. A League Table of Educational Disadvantage in Rich Nations. Geneva: UNICEF.

Villegas, A., \& Lucas, T., 2002. Educating Culturally Responsive Teachers: A Coherent Approach. New York: University of New York

Waitangi Tribunal, 1986. Report of the Waitangi Tribunal on the Te Reo Mãori Claim. [Internet.] [Retrieved 9th April, 2007.] Available from: http://www.waitangi-tribunal.govt.nz/scripts/reports/reports/11/2580F91B5D6F-46F4-ADE0-BC27CA535C01.pdf

Waite, J., 1992. Aoteareo. Speaking for ourselves. Wellington: Ministry of Education.

Walker, R., 1991. Liberating Māori from Educational Subjection. Monograph 6. Auckland: International Research Institute for Māori and Indigenous Education, University of Auckland.

Watts, N., 1989. Language and Communication: An Introduction. Palmerston North: Dunmore Press. 2 edn.

Williams, H., 1987. Broadcasting and the Māori Language. In W. Hirsh (ed.), Living Languages. Bilingualism and Community Languages in New Zealand. Auckland: Heinemann, pp. 99-105. 
Appendix A

\begin{tabular}{|l|}
\hline \multicolumn{1}{|c|}{ Teacher Interview Protocol } \\
\hline Time of interview: \\
Date: \\
Place/school: \\
Interviewee: \\
Position of interviewee: \\
\hline 1.The purpose of this study is to identify issues facing teachers, when using \\
Māori language in the classroom. This is to determine the effect language \\
use may have on students and ways of improving te reo use in schools. \\
Classroom teachers from a range of subjects will be interviewed and Māori \\
students will participate in a focus group discussion. No identifying \\
information will be used in the research and the tape recording will be \\
destroyed at the end of the project. This interview should take \\
approximately 15 minutes. Do you have any questions? \\
2.Please read, sign and date the consent form. \\
3.Turn on the recorder and test it. \\
Questions: \\
1.How long have you been teaching subject? \\
2.What place does Māori language have in your classroom? \\
3.What is difficult/easy about using Māori language? \\
4.In what ways do Māori students react to Māori language use in the \\
classroom? \\
5.Are there any other issues that affect your speaking of te reo in the \\
classroom? \\
6.Who else would you recommend I talk to? \\
Thank you for your time. \\
Do you have any questions or anything else you would like to say? \\
This interview will help identify the issues for teachers and be used to make \\
recommendations in my thesis. A summary of this thesis will be sent to your \\
school principal, but please contact me if you want further information (details \\
on the information sheet)
\end{tabular}




\section{Appendix B}

\section{Teacher Survey}

Please answer the following questions

\section{To begin with,}

1.Where did you train as a secondary school educator?

$\square$ Teachers college Name

$\square$ Overseas Name

$\square$ Other

2.How was Māori language part of your teacher training?

3.Have you had any Māori language training since then?

$\square$ No

$\square$ Yes, Please explain

4.How would you rate your ability in speaking Māori?

$\square$ Do not speak it $\square$ Beginner $\square$ Intermediate $\square$ Fluent

5.Are you interested in doing further Māori language professional development? $\square$ Yes $\square$ No $\square$ Maybe Please give reasons for your answer 
6.Do you think it is important, as a teacher, to pronounce te reo correctly?

$\square$ No

$\square$ Yes

For both answers: Why is this?

7.Do you think your te reo pronunciation affects your Māori students?

$\square$ No

$\square$ Yes, How?

8.In terms of using Māori language in the classroom what are the main issues for you as a teacher? E.g. too busy, lack of time for training, not confident. 


\section{Finally some questions about you}

1.What language do you consider to be your native or first language?

2.What other languages have you learnt?

Please choose up to three of your strongest languages and rate your ability for each one

$\begin{array}{cc}\text { No } & \text { Fluent } \\ \text { Ability } & \text { Ability }\end{array}$

3.How many years have you been working in secondary education?
口 $0-4$
$\square$ 5-9
10-14
15-19
$\square 20+$

4.What is your age group?
$\square$ 20-29
ㄴ 30-39
40-49
$\square 50-59$
$\square 60+$

5.What ethnic group do you mainly identify with?

$\square$ Māori $\square$ Pākehā/European $\square$ Other

6.Would you be willing to participate in follow-up interviews for this project?

$\square$ Yes

$\square$ No

If yes please write your name and a contact number below

\section{Thank you for taking time to do this survey Ngā mihi nui ki a koe}




\section{Appendix C}

\section{Student Survey}

Please answer the following questions.

1.Do you think all New Zealanders should pronounce te reo correctly?

Yes $\quad \square$ No $\square \underset{\text { matter }}{\text { Doesn't }} \square \underset{\text { Don't }}{\text { Dnow }}$
mater

2.Do you think all teachers should pronounce te reo correctly....

Never $\square$ Sometimes $\square$ Often $\square$ Always

3.How many teachers do you usually study with in a day?
$1-2$
$1-2 \square 3 \square$
4
5
6 or more

4.Of your teachers, how many mispronounce te reo?

Don't $\square 0 \quad \square$ 1-3 $\square$ 4-6 $\square$ k or more
know

5.Is it important for teachers to use Māori language in the classroom?

$\square$ No $\square$ Yes

Why is this?

6. What advice would you give teachers to improve their use of te reo in the classroom? 
Now some questions about you:

1.How would you rate your own ability in speaking te reo?

$\square$ Don't $\square$ Beginner $\square$ Intermediate $\square$ Fluent speak it

2.Do you study te reo?

$\square$ No $\square$ Yes

Why is this?

3.What year group are you?

$\square$ Yr9 $\square$ Yr 10 $\square$ Yr $11 \quad \square$ Yr $12 \quad \square$ Yr 13

4.If you have any other comments about Māori language use in schools, please write them here.

5.Would you be interested in talking to me about these questions further?

$\square$ No $\square$ Yes

If yes, please write your name and student I.D. below:

Ngā mihi nui ki a koe!

Thank you very much for your effort in answering these questions 


\section{Appendix D}

\section{Volunteer Information Sheet}

\section{Teachers}

Tēnā koe,

I am a secondary teacher of I.T./Computing and have taken leave to complete a Masters degree at Te Kawa a Māui (School of Māori Studies), Victoria University of Wellington.

The aim of my research is to understand what the issues are for staff and Māori students when teachers use Māori language in the classroom. This will help me to make some recommendations on future teaching training and practice, and educational policy.

Māori students may also benefit. By listening to their ideas and opinions of te reo use in the classroom we can acknowledge the importance of their experiences and hopefully help to improve student/teacher relationships.

Firstly, I will ask you to complete a short survey. If you volunteer to continue after this, I would like to interview you at least twice. These interviews will be recorded and should take approximately 15 minutes each time. You will have the chance to look over notes taken from these interviews and discuss any changes needed.

You can choose not to participate in the research at any time.

This research is confidential and at no time will you, the students or the school be identified in the results. It also has the approval of the university's human ethics committee.

The only person besides me to have access to my notes and recordings will be my supervisor, Peter Adds. Notes and tapes will be stored securely at all times and destroyed at the end of the project.

I hope to finish this project by the end of 2007 and I will send a copy of the summary to your school for you to read. You can contact me or my supervisor directly if you have any questions, or would like more information.

Janie Tito

Victoria University of Wellington

Te Kawa a Māui

P.O. Box 600

Phone: 04-4635314 or 0276547790

Email: jtito@hotmail.com 


\section{Appendix E}

Tēnā koe,

\section{Volunteer Information Sheet}

$\underline{\text { Students }}$

I am doing a Masters degree at Te Kawa a Māui (School of Māori Studies), Victoria University of Wellington. For this degree I need to carry out research in an area of interest to me.

The aim of my research is to find out what the issues are for you and your teachers when they use te reo in the classroom. The main reason for doing this research is that we need to find ways of helping you and other Māori youth do better at school and to help support teachers in using Māori language. If you volunteer, I would like to do the research in two parts:

Part 1 - I will ask you to fill in a short survey which will take about 5 minutes to complete

Part 2 - If you want to continue I will then talk to you in a group, at least twice. The first meeting will be to set ground rules and I would also like to get your opinion on how appropriate my questions/issues are. The second meeting will be to go into more depth about issues that you have told me are important. These group interviews will be recorded on tape and you will get the chance to read any notes taken and suggest changes. They will take approximately 1 hour each time. We will try and hold the meetings during lunch-times, but if during class-time I will need permission from your teachers.

You can choose not to participate in the research at any time and there is no pressure to answer questions if you do not want to. I will not talk about our group discussions with your teachers or other students.

This research is confidential, so nobody will be able to identify you, your teachers or school, by what you wrote or said. It also has the approval of the human ethics committee at the university.

The only person besides me to have access to my notes and recordings will be my supervisor, Peter Adds. Notes and tapes will be safely stored at all times and destroyed at the end of the project.

I hope to finish this by the end of 2007 and I will send a copy of the summary to your school for you to read. You can contact me or my supervisor directly if you have any questions, or would like more information.

Janie Tito

Victoria University of Wellington

Te Kawa a Māui

P.O. Box 600

Wellington

Phone: 04-4635314

Email: jtito@hotmail.com 


\section{Appendix F}

\section{$\underline{\text { Masters research - Janie Tito }}$}

\section{Māori language use in NZ secondary schools: What are the issues for teachers and students?}

\section{$\underline{\text { Teacher Consent Form }}$}

I have been given an information sheet on this research and I understand it. I have been given a chance to ask questions. I understand that I can pull out at any time without having to give reasons.

I understand that all the information I give will be kept confidential. The published results will not identify me or my school. I understand that the tape recordings of interviews will be destroyed at the end of the project, unless I want them returned to me.

I would like the tape recordings of my interviews returned to me at the end of the project. (Please delete if not applicable).

I understand that the information I provide will not be used for any other purpose or given to anyone else, without my written consent.

I understand I will have access to the results of the research at the end of the project.

I agree to take part in this research.

Signed:

Name (please print):

Date: 


\section{Appendix G}

\section{Masters research - Janie Tito}

\section{Māori language use in NZ secondary schools: What are the issues for teachers and students?}

\section{$\underline{\text { Student Consent Form }}$}

I have been given an information sheet on this research and I understand it. I have been given a chance to ask questions. I understand that I can pull out at any time without having to give reasons.

I understand that all the information I give will be kept confidential. The published results will not identify me or my school. I understand that the tape recordings of interviews will be destroyed at the end of the project.

I will not repeat what was said during the focus group discussion, to other people, in particular statements about students or teachers at this school.

I understand that the information I provide will not be used for any other purpose or given to anyone else, without my written consent.

I understand I will have access to the results of the research at the end of the project.

I agree to take part in this research.

Signed:

Name (please print):

Date: 